\title{
Environmental impacts of hybrid, plug-in hybrid, and battery electric vehicles - what can we learn from life cycle assessment?
}

\author{
Anders Nordelöf • Maarten Messagie • \\ Anne-Marie Tillman • Maria Ljunggren Söderman • \\ Joeri Van Mierlo
}

Received: 24 September 2013 / Accepted: 30 July 2014 /Published online: 21 August 2014

(C) The Author(s) 2014. This article is published with open access at Springerlink.com

\begin{abstract}
Purpose The purpose of this review article is to investigate the usefulness of different types of life cycle assessment (LCA) studies of electrified vehicles to provide robust and relevant stakeholder information. It presents synthesized conclusions based on 79 papers. Another objective is to search for explanations to divergence and "complexity" of results found by other overviewing papers in the research field, and to compile methodological learnings. The hypothesis was that such divergence could be explained by differences in goal and scope definitions of the reviewed LCA studies.

Methods The review has set special attention to the goal and scope formulation of all included studies. First, completeness and clarity have been assessed in view of the ISO standard's (ISO 2006a, b) recommendation for goal definition.
\end{abstract}

Responsible editor: Hans-Joerg Althaus

Electronic supplementary material The online version of this article (doi:10.1007/s11367-014-0788-0) contains supplementary material, which is available to authorized users.

A. Nordelöf $(\bowtie) \cdot$ A.-M. Tillman • M. Ljunggren Söderman • J. Van Mierlo

Division of Environmental Systems Analysis, Department of Energy and Environment, Chalmers University of Technology,

41296 Gothenburg, Sweden

e-mail: anders.nordelof@chalmers.se

M. Messagie - J. Van Mierlo

MOBI-Mobility, Logistics and Automotive Technology Research

Centre, Department of Electric Engineering and Energy Technology,

Vrije Universiteit Brussel, Pleinlaan 2, 1050 Brussels, Belgium

M. Ljunggren Söderman

IVL Swedish Environmental Research Institute, Box 530 21,

40014 Gothenburg, Sweden
Secondly, studies have been categorized based on technical and methodological scope, and searched for coherent conclusions.

Results and discussion Comprehensive goal formulation according to the ISO standard (ISO 2006a, b) is absent in most reviewed studies. Few give any account of the time scope, indicating the temporal validity of results and conclusions. Furthermore, most studies focus on today's electric vehicle technology, which is under strong development. Consequently, there is a lack of future time perspective, e.g., to advances in material processing, manufacturing of parts, and changes in electricity production. Nevertheless, robust assessment conclusions may still be identified. Most obvious is that electricity production is the main cause of environmental impact for externally chargeable vehicles. If, and only if, the charging electricity has very low emissions of fossil carbon, electric vehicles can reach their full potential in mitigating global warming. Consequently, it is surprising that almost no studies make this stipulation a main conclusion and try to convey it as a clear message to relevant stakeholders. Also, obtaining resources can be observed as a key area for future research. In mining, leakage of toxic substances from mine tailings has been highlighted. Efficient recycling, which is often assumed in LCA studies of electrified vehicles, may reduce demand for virgin resources and production energy. However, its realization remains a future challenge.

Conclusions LCA studies with clearly stated purposes and time scope are key to stakeholder lessons and guidance. It is also necessary for quality assurance. LCA practitioners studying hybrid and electric vehicles are strongly recommended to provide comprehensive and clear goal and scope formulation in line with the ISO standard (ISO 2006a, b). 
Keywords Battery $\cdot$ Electric vehicle $\cdot$ Hybrid $\cdot$ LCA . Meta-analysis $\cdot$ Well-to-wheels

\section{Introduction}

\subsection{Background}

Electric and hybrid powertrains are currently regarded as promising emerging technologies for propulsion of vehicles with potential to reduce greenhouse and other exhaust gas emissions from road transport (Nemry and Brons 2010; Sadek 2012). The arguments are that electric powertrains are more energy efficient for propelling vehicles than conventional internal combustion engines fuelled by petrol or diesel, and that full electric propulsion does not emit tailpipe emissions (IAE 2011; Sadek 2012). In addition, electric powertrains can assist in decoupling the transport sector from its heavy reliance on fossil fuels. On the other hand, electric vehicles may require additional electricity production (Tran et al. 2012) and this can be done using several different energy sources with diverse environmental impacts. Furthermore, electric powertrains require new advanced components (Chan 2007), causing additional, or at least different, environmental impacts compared to conventional vehicles.

The trade-off between the benefits when operating the vehicle and possible new or increased negative impacts from production and from energy supply can be analyzed using life cycle assessment (LCA). However, LCA studies come in many shapes and cause diverging arguments about the environmental performance of the technology on which they are based. Some advocate the technology, for example, using the well-to-wheels approach to guide government promotion policies toward different types of powertrains and alternative fuel options (Ou et al. 2010b). Others claim that the prospective for electric cars to reduce the environmental impacts of mobility is "substantially overrated" (Frischknecht and Flury 2011) or that they will lead to "significant increases in human toxicity" (Hawkins et al. 2013a).

Few reviews have been carried out in the field of LCA of electric vehicles, synthesizing results and assessing the scope of the research field. In the most thorough, Hawkins et al. (2012) benchmarked 55 studies and surveyed what 51 of them cover in terms of scope compared to their own recommended practice and definition of a state-of-the-art complete LCA of electrified vehicles. The review commendably discusses and evaluates the datasets used in the research field, and identifies gaps in the inventories of the main components such as batteries, electric motors, and electronic equipment. It also presents an analysis of greenhouse gas (GHG) emissions for the complete life cycle across studies, including meta-analysis of the effect of assumptions regarding lifetime on impact from production of equipment and discussions on how battery production and use phase energy efficiency affect the results. Additionally, the history of life cycle assessments of electrified vehicle is summarized; various technical aspects of vehicle electrification such as charging management is described and uncertainty in results is discussed. Among conclusions, Hawkins et al. (2012) do not find any of the reviewed 51 studies to comply with their definition of how a complete state-of-the-art LCA of electrified vehicles should be conducted, and hence request more rigorous and complete inventories and studies. The quality of "stylized studies," described as studies based on rudimentary inventories and a low level of detail, is questioned. It is argued that such studies have limited utility for informing policy makers as they only cover limited subsets of the complete system (Hawkins et al. 2012).

Another paper by Helmers and Marx (2012) compiles a broad description of technical characteristics and environmental impacts of electric and hybrid vehicles, however without focus on literature evaluation. They conclude that electric vehicles have many benefits over conventional ones, but that the LCA literature on the subject "is complex." Overviews are also provided in a conference report by Frischknecht and Flury (2011), in an appendix to a case study by Ma et al. (2012) and an editorial by Althaus (2012). Althaus (2012) observes that results come out as diverging and that there is "a rather weak consensus" on the environmental performance of electric vehicles. Also, Frischknecht and Flury (2011) argue that results are diverging and, as an example, mention that emissions for electric vehicles vary between 95 to $240 \mathrm{~g} \mathrm{CO}_{2}$ eq. $/ \mathrm{km}$.

In contrast, we argue that the numerical results in any system study, such as LCA, is dependent on its purpose or, more to the point, which specific problem or question it is investigating (see for example Sterman (1991)). In LCA, the formulation of the purpose is made during what the international standard for LCA (ISO 2006a, b) defines as the goal and scope definition. The scope consists of the methodological choices made to address the stated goal, ensuring that the conclusions of the study are sufficiently supported, for example in selection of technical scope, time horizon, and level of impact assessment. But, from going through the literature in the field, it is evident that while the scope (i.e., the modeling choices) at large, except for the time frame, is mostly well described in LCA studies of electric and hybrid vehicles, the goal is sometimes expressed vaguely and even partly, or fully, left out. As a consequence, there is a risk that the research field appears unnecessarily complex and provides seemingly diverging results, in particular if common messages are sought from studies with very different goal and scope. Unclearly articulated purposes of studies make it necessary to go into the details of each study to find the motivation for its limitations and underlying assumptions. This may also disguise that consensus can be found in several main conclusions from 
studies with similar scope. As a consequence, stakeholders within the area of vehicle electrification, such as policy makers and various branches of industry, might end up without guidance when it could have been, and was intended to be, given.

\subsection{Purpose}

The purpose of this review is to investigate the usefulness of different types of LCA studies to provide relevant information to stakeholders in the area of vehicle electrification, to tease out general and robust conclusions, and to exemplify with results. We thereby intend to complement the work of Hawkins et al. (2012), recognizing that there are many possible goals for LCA studies of electrified vehicles and applying a learning perspective to the field. A parallel objective is to examine the inconsistency of results observed by other overviewing literature (Althaus 2012; Frischknecht and Flury 2011; Helmers and Marx 2012). Our hypothesis is that if comprehensive and detailed goal and scope formulation is not sufficiently reported, the results in the research field will appear diverging and inconsistent.

The review addresses industrial managers, governmental agencies, and other institutions seeking advice and guidance from LCA studies. It investigates what set of methodological choices provide answers to what questions. More specifically, which answers do stakeholders get from so-called well-towheels (WTW) studies in comparison to complete LCA studies? What difference does it make if a study includes a narrow or broad set of environmental impacts, and if different types of impact assessment are conducted? Other target groups are scientists and industrial practitioners conducting and developing LCA in the field of electrified vehicles. In particular, the investigation of goal and scope is compiled into methodological learnings for an LCA specialist audience.

\subsection{Reading guide}

In Section 2, we provide an account of the methodology used in the review, such as the criteria for literature inclusion and a description of the analysis made in the review process. Section 3 supplies a technical background to the scope of the paper. Section 4 presents a methodological background and various aspects of the goal and scope formulation as found in current literature and in the ISO standard (ISO 2006a, b), including its connection to different types of uncertainty in LCA and different life cycle scope in LCA of vehicles. Next, in Section 5, focus is set on the results of the literature analysis. First, in subsection 5.1, the communication of goals and the selection of scope in the reviewed papers are investigated. This is followed by an analysis of energy use and GHG emissions for different life cycle scopes in sections 5.2 and 5.3, before additional environmental impacts are investigated in
Section 5.4. Lastly, lessons are discussed and formulated into conclusions in Section 6, both in terms of assessment results and in terms of methodological learnings.

\section{Methodology}

\subsection{Inclusion of literature}

A review of, in total, 79 scientific articles, conference papers, and reports on life cycle assessment of electric and hybrid vehicles published in the time period from 1998 to early 2013 has been conducted. All studies include at least one vehicle with an electric or partly electric powertrain, with a battery as the on-board electric energy storage. Fuel cell-based electric powertrains are not included in the evaluation, although such are covered in several of the reviewed papers.

To the authors' best knowledge and access, all peerreviewed papers found in established scientific journals are included. The review also includes all conference papers encountered in the search process. Studies presented in gray literature from universities and established research institutes have been included when sufficient documentation has been found. In some cases, very similar papers were found, both as a conference paper and a later published peer-reviewed paper. The latter were then chosen for the review.

\subsection{Review approach}

The starting point, and continued goal of this review, is to identify robust lessons and learnings from LCA about the environmental impacts of electrification of vehicles. A structured evaluation of literature has been conducted and a search for consensus among studies. Reviews may utilize a large range of methods to synthesize conclusions from the best available evidence (Zumsteg et al. 2012), including various forms of meta-analysis, quantitative and qualitative, grouping, and statistical summaries.

In this review, qualitative meta-analysis provides evidence for the robustness of the key conclusions. We address the coverage of the literature by analysis of the goal and scope definition. Further, we investigate key factors behind assessment results of studies by analysis of their discussion of results and conclusions. More in detail, several tables statistically present the degree of consensus in statements formulated on prevalent topics of investigation within a certain scope. First, the reporting of goals and time frame were compared with the recommendations provided by the ISO standard (ISO 2006a, b). Second, all included studies were sorted into categories and presented according to what they cover in terms of vehicle technology and impact. Third, we investigated what set of methodological choices provide answers to what questions, or phrased differently, we tried to link the selection of scope to 
corresponding goals, regardless of how the goal of each study has been stated; clearly, vaguely, or not all. This was achieved by asking what we can learn from the different categories and by qualitatively synthesizing the assessment results and conclusions into lessons and learnings for different stakeholders.

All studies included in the review have been qualitatively meta-analyzed. Relevant topics, i.e., questions which can be addressed by the different categories of LCA studies, were identified, for example "the influence of supplied electricity for charging." The prevalence of these topics was investigated. Next, a statement about each topic was defined, e.g., that the "supplied electricity for charging is a key factor for the results." The coverage of topics and evidence for support or refutation of statements was sought for in tables, figures, and texts coupled to results, discussion of results, and conclusions. Finally, the results for the support of statements were summarized statistically in relation to the total number of studies covering the topic and compiled into tables, presented in section 5. An exception is the topic of resource use for equipment manufacturing which is addressed in a gap analysis.

Additionally, quantitative meta-analysis of some selected studies is used to reflect consequences of certain important methodological choices. The effect of different electricity supplies for charging is illustrated by varying input data for electricity in a reconstructed LCA model of one specific study. Similarly, the importance of lifetime assumptions for equipment results is investigated through quantitative analysis of sensitivity to the value for lifetime driven distance in three selected studies. Common for all studies used for quantitative meta-analysis is that they provide transparent and sufficiently detailed accounts of calculation procedures and input data, to allow these single modifications. Even so, the ambition has not been to harmonize system boundaries and create comparable numerical results. Instead, the authors acknowledge that each LCA study is uniquely specified by its own methodological choices. This inherent property of system studies leads to significant challenges for easy but relevant comparison of quantitative results across studies and harmonization of numerical results (Brandão et al. 2012; Farrell et al. 2006; Zumsteg et al. 2012).

Indeed, deeper quantitative meta-analysis of LCA studies is sometimes conducted, such as by Farrell et al. (2006) with six studies within the area of biofuels. The results of the selected studies were reproduced with altered and thereby comparable final numerical results. However, this may only be done if enough information is accessible to change and fully harmonize the system boundaries. In contrast, our review includes a large number of studies with different life cycle and technical scope, and very varying level of detail in the methodology account. Also, the adoption of a learning perspective calls for a survey of key conclusions, rather than key numbers. Anyhow, given the parallel focus on goal and scope definition, the review examines prerequisites and possibilities for future, more ample, numerical harmonization of a subset of studies for those who wish to seek it.

In general, example results from single or only a few sources are shown as illustrations of the type of information contained within a certain scope. When such examples also are pointed out as "typical," it is based on the observations and judgments of the authors. All exemplifying results derive from studies with sufficiently clear information about assumptions, calculations, and data, either available in literature or from the corresponding author upon request.

For more information about all presented tables and figures, please see the Electronic Supplementary Material.

\section{Technical background}

\subsection{Powertrain aspects}

An electric powertrain can be realized in several different configurations. Whichever way, it requires a set of advanced electrical components such as one or more electric machines to provide motoring and generating capacity. Electronic power devices are used to control the electric machines, to modify the voltage, and to shift between AC and DC currents. There is often a mechanical power path to the wheels, with many design options, just as in conventional vehicles. In hybrid vehicles, the electric propulsion system is combined with the conventional powertrain, either to achieve better driving performance as in a "power hybrid" or with the internal combustion engine (ICE) downsized aiming for increased energy efficiency and emission reduction (Chan 2007).

Additionally, there is a need for electric energy storage, most commonly realized as a battery. However, there is reason to differentiate between batteries which can be externally charged with electricity from the grid, referred to as "plugin," and those which are entirely charged by the ICE and brake energy recovery within the vehicle. If the vehicle is externally charged, the battery is often optimized to store energy and for a use pattern where it is alternately fully charged and depleted (Corrigan and Masias 2011). In the other case, the battery is optimized to provide electric power (rather than energy) and to sustain the same charge level all the time. The life length of a battery is dependent on several complex and interacting mechanisms relating to cell chemistry combined with storage and charging and discharging conditions such as temperature, cycle depth, and different forms of chemical degradation (Corrigan and Masias 2011; Vetter et al. 2005). Examples are decomposition of active materials, corrosion, and oxidation of various surfaces (Vetter et al. 2005). Hence, the ageing process is dependent both on the number of charging cycles, i.e. how much the battery is used, and on calendar time.

Electric powertrains can be realized in many different configurations and are relatively novel in modern automotive 
applications (Chan 2007). This implies that there are timerelated assumptions made in LCA studies with influence on results, but also that there is a large improvement potential for the future. Electric motor manufacturing is one area where material and energy use can be saved by adapting motor design for manufacturing (Hellsing 2013) as well as for recycling (Machacek 2012). Moreover, electric motors developed for automotive traction applications are currently not produced in any large series and there is low energy efficiency in manufacturing compared to other automotive components (Hellsing 2013).

In the case of lithium-ion batteries, it is the production of battery cells which is most energy demanding (Volkswagen Group 2012), and more specifically the processing of the active materials (Dunn et al. 2012). While each chemistry has a number of viable synthesis procedures, there are a number of very energy-intensive processes, such as grinding cathode materials down to very fine particles (Kushnir and Sandén 2011) that are sometimes needed depending on the desired properties of the final material. Various types of tailored improvements with regard to process, cell, and the overall component design along with increased production scale are predicted to moderately but steadily increase performance and reduce cost over the coming 5 years according to the National Research Council (2013) in the USA. These types of advances are also coupled to decreased material and energy use. Additionally, in a longer time perspective, battery recycling may offer both economic and environmental benefits (Li et al. 2013). Gaines et al. (2011) find that recycling may reduce material production energy demand by as much as $50 \%$. Another long-term improvement possibility is the use of nanotechnology to enhance performance and durability of lithium-ion batteries (Kushnir and Sandén 2011). Although such a step would probably increase the production energy demand, it still has the potential to lower the overall life cycle energy (Kushnir and Sandén 2011).

\subsection{Vehicle terminology}

The term "hybrid electric vehicle" (HEV) is used to describe a vehicle with both an electric motor and an ICE, but without external charging. Different HEVs may still have different sizes of battery and consequently different degrees of electric propulsion. This spans from regeneration of brake power and assistance to the ICE (mild hybrids) to include a certain distance of pure electric driving (full hybrids). The distinction, however, is not often accounted for in the reviewed LCAs. "Battery electric vehicles" (BEVs) have batteries adapted for external charging, no ICE and drive purely on electric energy. The plug-in hybrid electric vehicle (PHEV) runs on externally charged electricity but enters a blended hybrid mode of electric motor and ICE operation when the battery has been depleted. The maximum distance a PHEV can cover without any engine support is called the "all-electric range." Conventional vehicles are always propelled by an ICE and are in this text referred to as "internal combustion engine vehicles" (ICEVs).

Vehicles come in various sizes, implying different weights, which is a key factor for environmental performance (Frischknecht and Flury 2011). A passenger vehicle classified as "small family-sized" is roughly of the same size as one classified as a "compact car" or "C-segment," i.e., they belong to the same size and performance class or segment. Examples of vehicles in this segment are Volvo C30, Ford Focus, VW Golf, and Nissan Leaf. Smaller vehicles are often classified as city or supermini cars (A and B segment) and that could be a Fiat Punto, Citroen C1, Peugeot 106, or Smart. For larger vehicles, there is a whole range of segments. Examples of larger family cars (D-segment) include Volvo V60, Toyota Prius, and Ford Mondeo, and an executive car (E-segment) is the Volvo S80. Even larger segments are called luxury cars (Fsegment, e.g., Lexus LS, Mercedes S-Klasse), monovolumes (M-segment, e.g., Ford S-Max), and sport utility vehicles (Jsegment, e.g., Lexus RX and Mercedes M-Klasse). Today's BEVs are normally city or compact cars, PHEVs are often within the family and executive vehicle span, and HEVs can be found in all segments. The letter system for segmentation classes A, B, C, etc. have been proposed by the European Commission but have no strict definition. For more details, please see the Electronic Supplementary Material.

Heavy vehicles such as busses, distribution trucks, and long haulers can also be electrified, and are then mostly found as hybrids without the possibility of external charging. City buses have a particularly large fuel-saving potential and can also be found in plug-in hybrid or all-electric versions.

\section{Life cycle assessment of road vehicles}

\subsection{Overview and purpose formulation}

LCA is a systemic tool for evaluating the environmental impact related to goods and services. It includes technical surveys of all product life cycle stages, from material acquisition and manufacturing to use and end-of-life. Data is gathered for inflows and outflows at each stage. By linking processes within the system from cradle to grave, a model is made of how the flows are connected and influence each other. This results in an inventory of inflows to the system in terms of natural resources and outflows in terms of emissions to the surrounding natural system. The inventory is then analyzed to indicate potential for environmental impacts in various categories, such as global warming, human toxicity, and acidification. (ISO 2006a)

An LCA study of a vehicle can be conducted in different ways, but not arbitrarily. The selection of scope and other methodological choices are subordinate to the purpose formulation. The ISO standard (ISO 2006b) requires that the 
goal and scope must be "clearly stated and consistent with the intended application." Furthermore, the standard states that the goal "shall unambiguously state the intended application, the reasons for carrying out the study and the intended audience, i.e. to whom the results of the study are intended to be communicated" (ISO 2006a, b). Similar recommendations are given in the eLCAr guidelines for the LCA of electric vehicles (Duce et al. 2013). The latter also points out that a clear goal definition is essential for a correct later interpretation of the results (Duce et al. 2013). The subsequent scope definition should then be sufficiently well defined to ensure that the coverage and the detail of the study are compatible and sufficient to address the stated goal (ISO 2006a). For example, it includes specifying the functions of the system being studied, allocation procedures, life cycle impact assessment (LCIA) methodology, limitations, and technological as well as geographical system boundaries. The system boundaries also include a time scope, i.e., a time-related coverage of the study. This information is a prerequisite to evaluate the timerelated representativeness of the data used and the temporal validity of the results. We argue that the time scope is especially important in the case of an emerging technology which is likely to change over time. Likewise, the scope definition example of the eLCAr guidelines (Duce et al. 2013) includes a very clear time scope statement.

Several factors determine the system boundaries, including the intended application of the study and the intended audience. Surprisingly enough, these goal considerations along with the time scope are not always fully presented in the scientific literature covered in this review. However, by investigating the actually selected system boundaries and other methodological choices, it is possible to identify implicit questions and problems typically addressed by a group of studies, and then to match these with relevant target groups.

\subsection{Life cycle scope}

The WTW study is one type of LCA of vehicles, which focuses on the life cycle of the energy carrier used to propel the vehicle, such as liquid fuel or electricity (see Fig. 1). The WTW life cycle can be subdivided into the well-to-tank (WTT) stage, which focuses on the delivery of energy from its source to the storage equipment in the vehicle, and the tankto-wheel (TTW) stage, where the energy carrier is used to propel the vehicle during operation. The WTT stage involves all processes from harnessing a primary energy flow or stock to different forms of conversion, distribution, and storage of energy carriers. The environmental burden of the WTT stage differs a lot, depending on how the energy carrier is produced. For example, there is a large difference between electricity produced from hydropower- and coal-fired plants.

In the case of liquid fuels, the TTW stage typically results in both exhaust and evaporative emissions (MacLean and
Lave 2003). For pure electric vehicles charged from the grid, the TTW stage involves no emissions at all. Nevertheless, the TTW is still important as different powertrain configurations have different efficiencies and energy losses, which affect the overall results of the WTW.

The vertical flow in Fig. 1 represents the life cycle of the vehicle itself, which is sometimes referred to as "cradle-tograve" (Baptista et al. 2011; Messagie et al. 2010; Van Mierlo et al. 2003a) or as "vehicle cycle" (Gao and Winfield 2012; Jaramillo et al. 2009; Lane 2006). In this text, we introduce the term "equipment life cycle" - in line with terminology used in the ISO standard (ISO 2006a). In addition, this term is more generic, since it is applicable also to studies of powertrain or component levels. This way of dividing the complete life cycle into two main flows is common in vehicle LCA (Baptista et al. 2011; Gao and Winfield 2012; Jaramillo et al. 2009; Lane 2006; Messagie et al. 2010; Van Mierlo et al. 2003a). For studies where all processes are included, i.e., both the WTW and equipment life cycles, the term "complete LCA" is used hereinafter.

The first processes in the equipment life cycle consist of raw material extraction and material processing. They are followed by manufacturing, where parts are fabricated and assembled into a vehicle. The subsequent activity is the vehicle operation, which is also where WTW life cycle of the energy carrier and the equipment life cycle are connected. However, some aspects of the operation are solely connected to the equipment life cycle, namely service and reparation, shown in Fig. 1 as maintenance. The final stage, the end-oflife, involves dismantling and recovery of certain parts, as well as shredding, recycling, and disposal of residues.

\subsection{Uncertainty}

The assessment of quality and robustness of results in LCA is referred to as uncertainty analysis, which is of particular relevance for LCA of an emerging technology, such as electrified vehicles. Thorough review and in-depth discussions about uncertainty in LCA can be found in, for example, Heijungs and Huijbregts (2004) or Lloyd and Ries (2007). The topic is also covered by broad LCA methodology reviews such as Finnveden et al. (2009).

Heijungs and Huijbregts (2004) argue that different types of uncertainties can be defined at different levels: parameter, scenario, and model uncertainty. Parameter uncertainty is coupled to the fact that parameters may be very difficult to measure with high precision or are inherently variable. It may be addressed by incorporating mathematical tools for error propagation from the data input to the life cycle results. For vehicles, Boureima et al. (2009) have presented a "rangebased" model where representative statistical distributions are calculated from collected vehicle data. However, when it comes to impact assessment, uncertainty estimates for error 


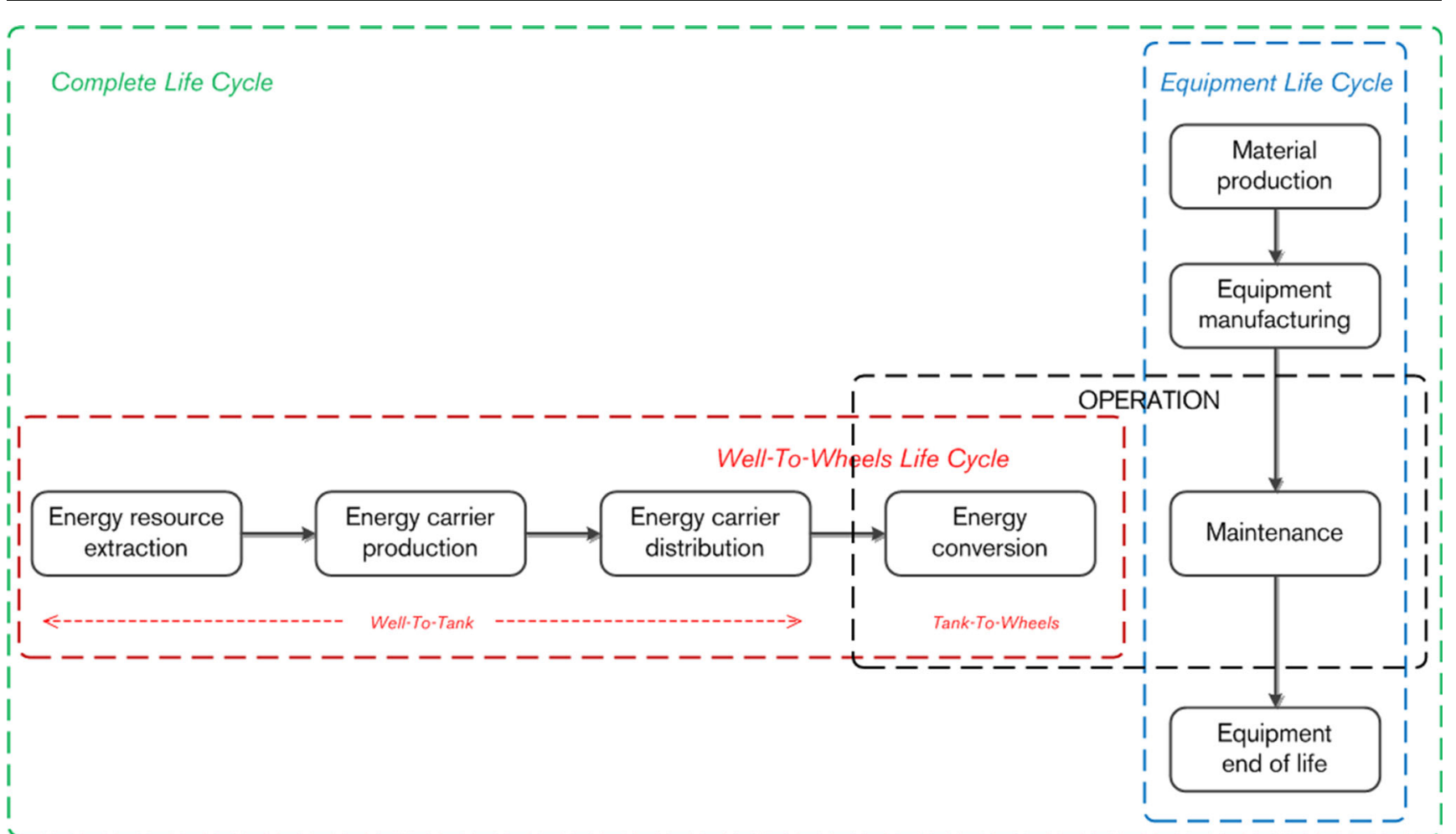

Fig. 1 Simplified view of the well-to-wheels and equipment flows (a more detailed view would include, for example, recycling options)

propagation are only provided for one of the established impact categories, the global warming potential (Hauschild et al. 2013).

Scenario uncertainty may be addressed by avoiding predictions and instead use stylized states. In this case, a "stylized state" denotes an extreme state (e.g., a state where all electricity and heat are produced from coal) that is unlikely to materialize, but that could illustrate important technology differences in a clear way, as defined by Hillman and Sanden (2008). The stylized state can then be regarded as a mean to "test" the technology at some system limit and thereby identify its inherent properties. Another possibility is to use several explorative scenarios (Finnveden et al. 2009). Model uncertainty may be addressed by having a well-formulated goal and scope definition, and construct the model accordingly, with system boundaries chosen to reach the goal of the study and a suitable level of detail in the technical representation of the system (Tillman 2000).

\section{Results of literature analysis}

\subsection{Goal and scope formulation}

\subsubsection{Reporting of goals and time frame}

In the review of the 79 papers on life cycle assessment of electric and hybrid vehicles, special attention was given to goal statements and time frame. In line with ISO (2006a, b), the comprehensiveness of the goal formulation was examined based on three reporting criteria-the reason for carrying out the study, the intended application, and the intended audience. In addition, following from the discussion in section 4.1, the declaration of a time scope was selected as a fourth criterion for evaluation. All types of statements about these four criteria, including vague or indirect formulations, were searched for.

The result of the evaluation is presented in Table 1. At first sight, it can be noted that the first two criteria are met by roughly three quarters of all studies. However, this appearance is a little deceptive, as some studies fulfill one of the first two criteria, but not the other. In combination, more than a third of all evaluated studies lack either the intended application or the reason for conducting the study. Furthermore, only 14 of 79 studies state an intended audience and 20 some kind of time frame. This also includes vague statements such as "decision makers" as the audience (Hackney and de Neufville 2001; Harto et al. 2010) or "2015 and beyond" (Ma et al. 2012; Van

Table 1 Number of studies reporting goals according to ISO (2006a, b) and with time scope

Studies reporting the reason for carrying out the study $\quad 77 \%$ Studies reporting the intended application $\quad 73 \%$ Studies reporting the intended audience $\quad 18 \%$ Studies reporting a time frame for the study $\quad 25 \%$ 
Vliet et al. 2011) as the time scope. Eleven studies, reported in peer-reviewed journals or conference literature, have no study goal formulated at all. Six of these 11 also lack the time scope.

It was found that only 1 of 79 references made all the requested information available, Brinkman et al. (2005), by referring back to an earlier report by GM et al. (2001) in the same series. The purpose is "to help inform public and private decision makers about advanced propulsion system pathways." The papers most frequently cited generally account well for both the motive behind and the application of the study, but leave out the time frame and intended audience (Samaras and Meisterling 2008a; Notter et al. 2010a). A good example of the goal formulation among the reviewed papers can be found in Kliucininkas et al. (2012), but it lacks the time scope. Another useful example within LCA of vehicles, but not included in this review as it does not concern any electrically propelled vehicle, has been provided by Spielmann and Althaus (2007). It includes an overall goal of the research as well as three specific questions under study and a time scope (Spielmann and Althaus 2007). Also, several stakeholders are mentioned in the paper, although no specific intended audience is highlighted.

\subsubsection{Scope of analyzed studies}

In terms of technical scope, most studies model the whole vehicle, or at least the powertrain, using a similar level of detail. A different, but also quite common technical scope, is to focus on the battery, either in a complete LCA, as placed in a vehicle, or considering only the equipment life cycle in a component study. The reason for the extra attention on battery technology is a consensus among all studies over the traction battery being a key component in terms of weight, performance, and durability, as pointed out by Frischknecht and Flury (2011).

Table 2 shows a compilation of all 79 reviewed papers and reports. They are divided into three groups, depending on their scope-WTW studies, complete LCAs, and battery LCAs. The table provides an overview of the research field and what the different groups of studies cover in terms of vehicle technology and impact assessment. The functional unit is the entity to which all data in a study is correlated. With regards to complete LCA, it is notable that the assumed vehicle lifetime (in $\mathrm{km}$ ) differs widely between studies. The strong focus on light passenger vehicles and greenhouse gas emissions is also evident in Table 2.

5.2 What can we learn from well-to-wheels studies?

\subsubsection{Electricity supply and efficiency}

Powertrain electrification can potentially reduce GHG emissions by increasing TTW efficiency and by making it possible to abandon energy produced from fossil fuels in the WTT stage. For all vehicles, especially if propelled with externally charged electricity (BEVs and PHEVs), GHG emissions depend on the entire WTW life cycle. Consequently, it is common to adopt the WTW perspective when the purpose of a study is to assess the efficiency of different powertrain options, to assess the climate impacts of different energy carriers, and to examine how electricity production influences vehicles' environmental performance. Comparative WTW studies are relevant for vehicles of similar size, weight, and electric driving range.

In a large WTW study commissioned by the European Union, externally chargeable electric vehicles in the compact class were compared with conventional vehicles with respect to GHG emissions based on the standard European driving cycle (NEDC) (Edwards et al. 2011a, b). Three generic types of vehicles with different degrees of electrification were defined: PHEVs, BEVs, and "extended range electric vehicles" (E-REVs). Study data was based on prototypes and development vehicles with batteries and electric motors in a range of different sizes to provide a worst (maximum) case and a best (minimum) case for each category. Use of liquid fuel was limited to petrol. The PHEV category has limited electric performance and an all-electric range of 20-40 km, with start-up in either pure electric or blended hybrid operation. The E-REV category refers to vehicles having all traction performed by the electric motor using the internal combustion engine only for generating electricity to charge the battery and thus extend the range of the vehicle above the electric range of 60-80 km. Finally, the BEV category includes vehicles propelled entirely by externally produced electricity, with a driving range span of 120-160 km. These vehicles were compared to a reference case defined as a petrol-driven ICEV with tailpipe emissions of $120 \mathrm{~g} \mathrm{CO}_{2}$-eq. $/ \mathrm{km}$. Tailpipe emissions refer to the TTW stage and correspond to $143 \mathrm{~g} \mathrm{CO}_{2}$-eq. $/ \mathrm{km}$ for the full WTW (Edwards et al. 2011b).

Figure 2 displays the results of the EU WTW analysis. The bars on the right show the different generic-type vehicles based on the average EU electricity mix (467 $\mathrm{g} \mathrm{CO}_{2}$-eq./kWh in 2008 (Maas 2013)). As can be seen, all electrified vehicles have lower emissions than the reference case. The data also demonstrates a reduction in GHG emissions with an increasing degree of electrification, although different vehicle categories overlap with regard to minimum and maximum values.

The bars to the left in Fig. 2 show how different means of electricity production give altered WTW GHG emissions for the BEV category. As expected, they increase with higher electricity GHG intensity, and above around $900 \mathrm{~g} \mathrm{CO}_{2}$-eq./ $\mathrm{kWh}$, roughly what oil-fired power production cause according to the EU study, the BEV vehicle emits more than the reference vehicle. It is clear that carbon-intensive electricity production results in strikingly higher emissions than renewable electricity, in this case represented by wind energy. 

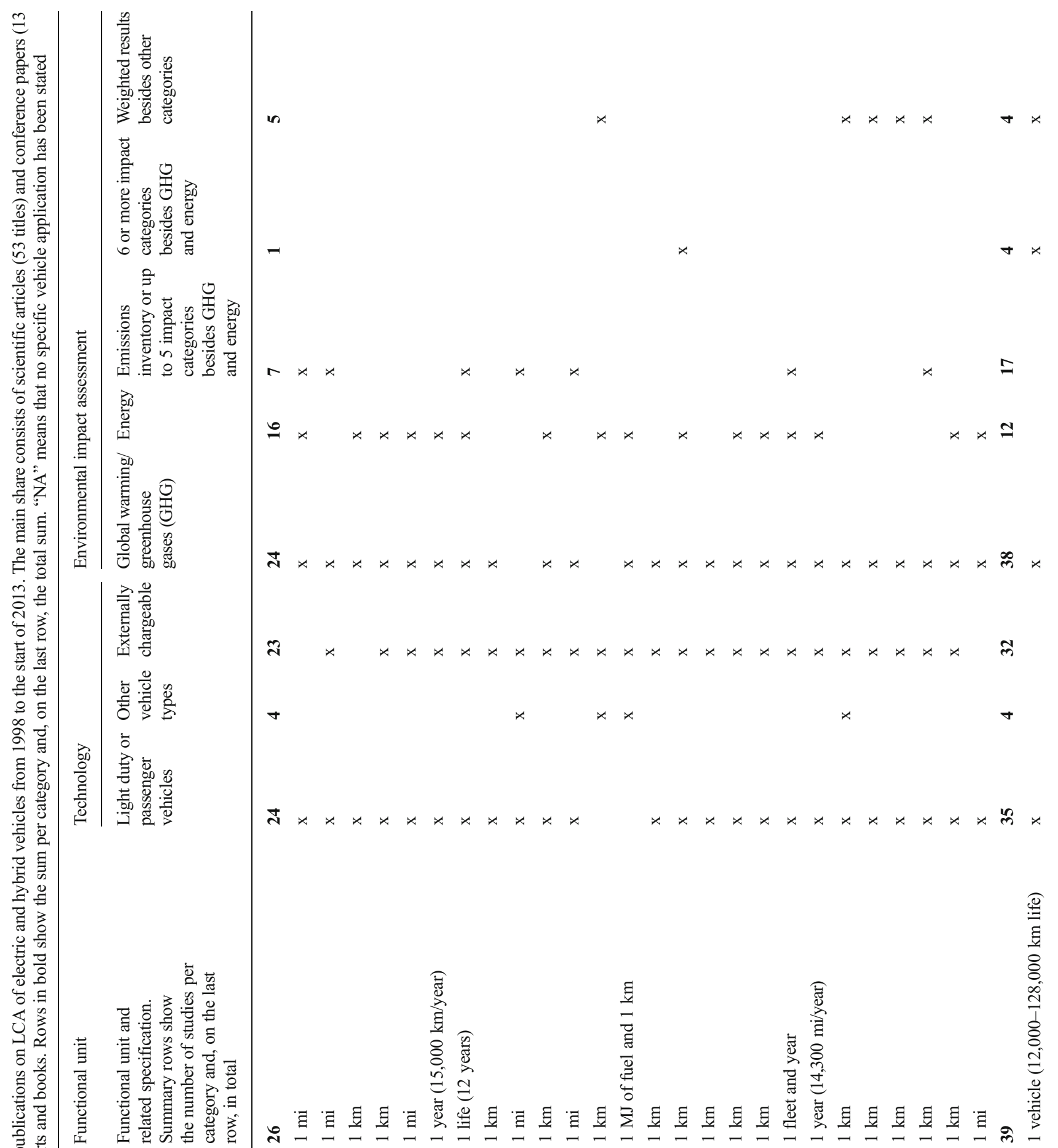

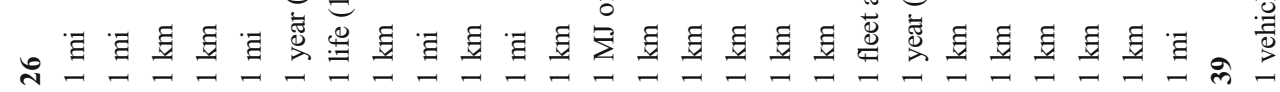

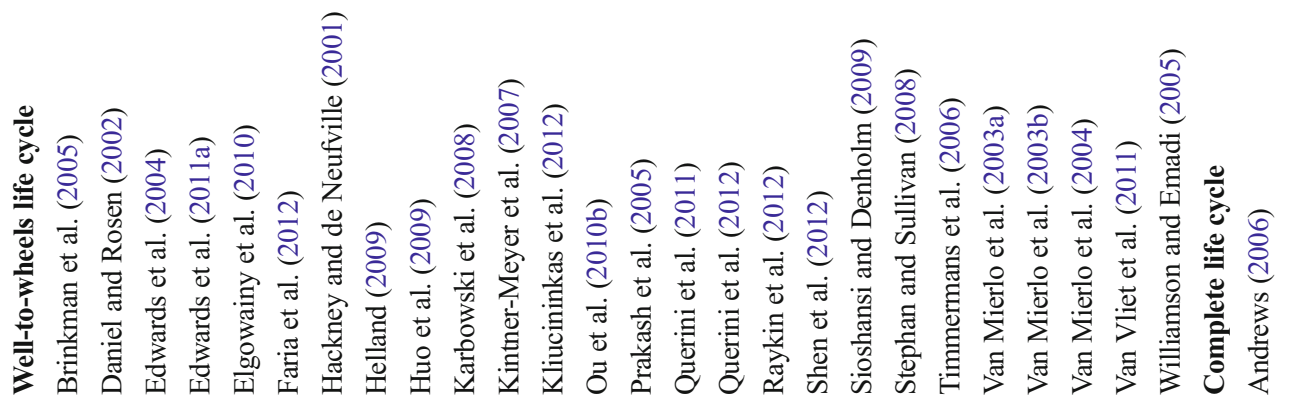




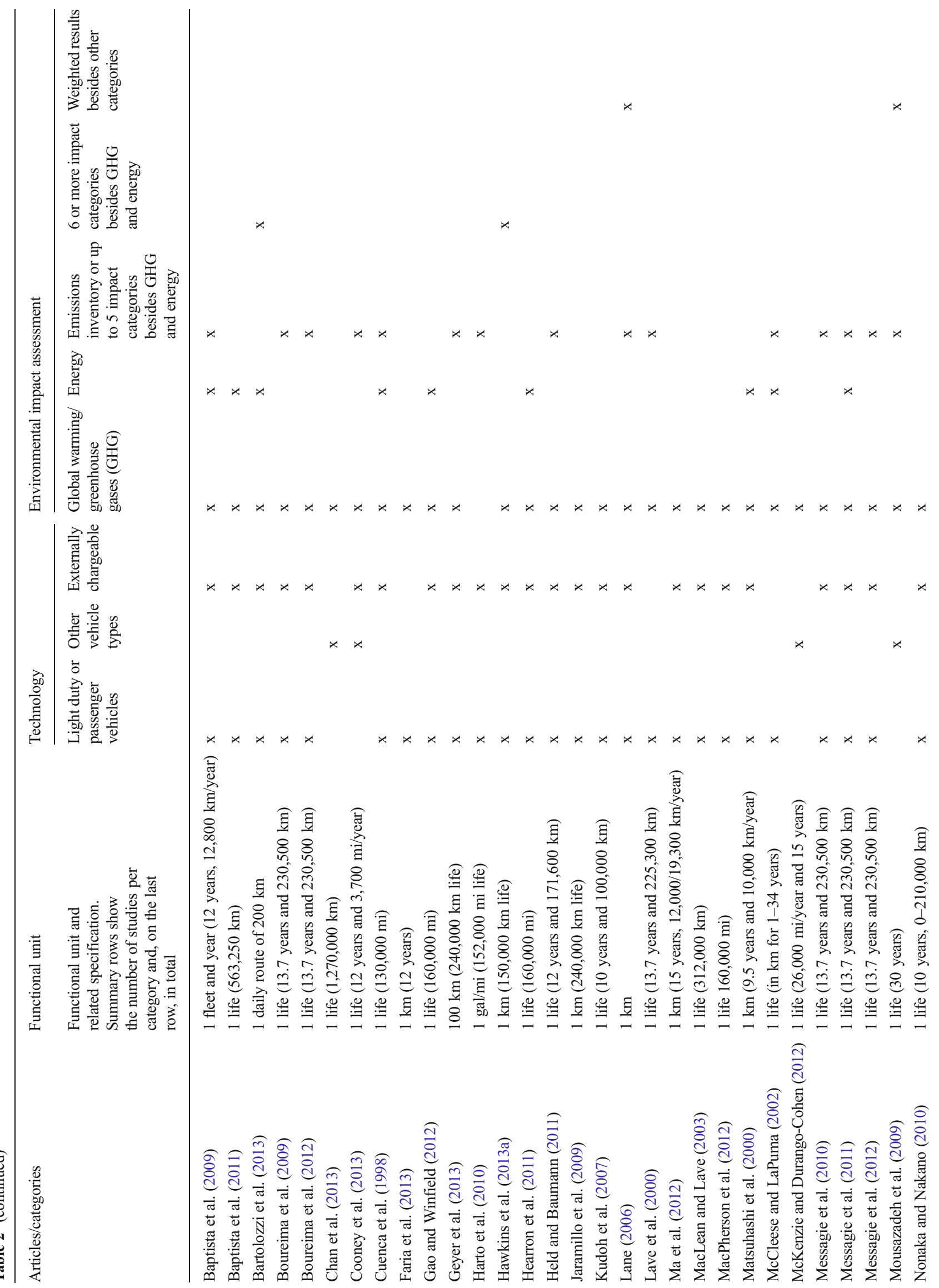




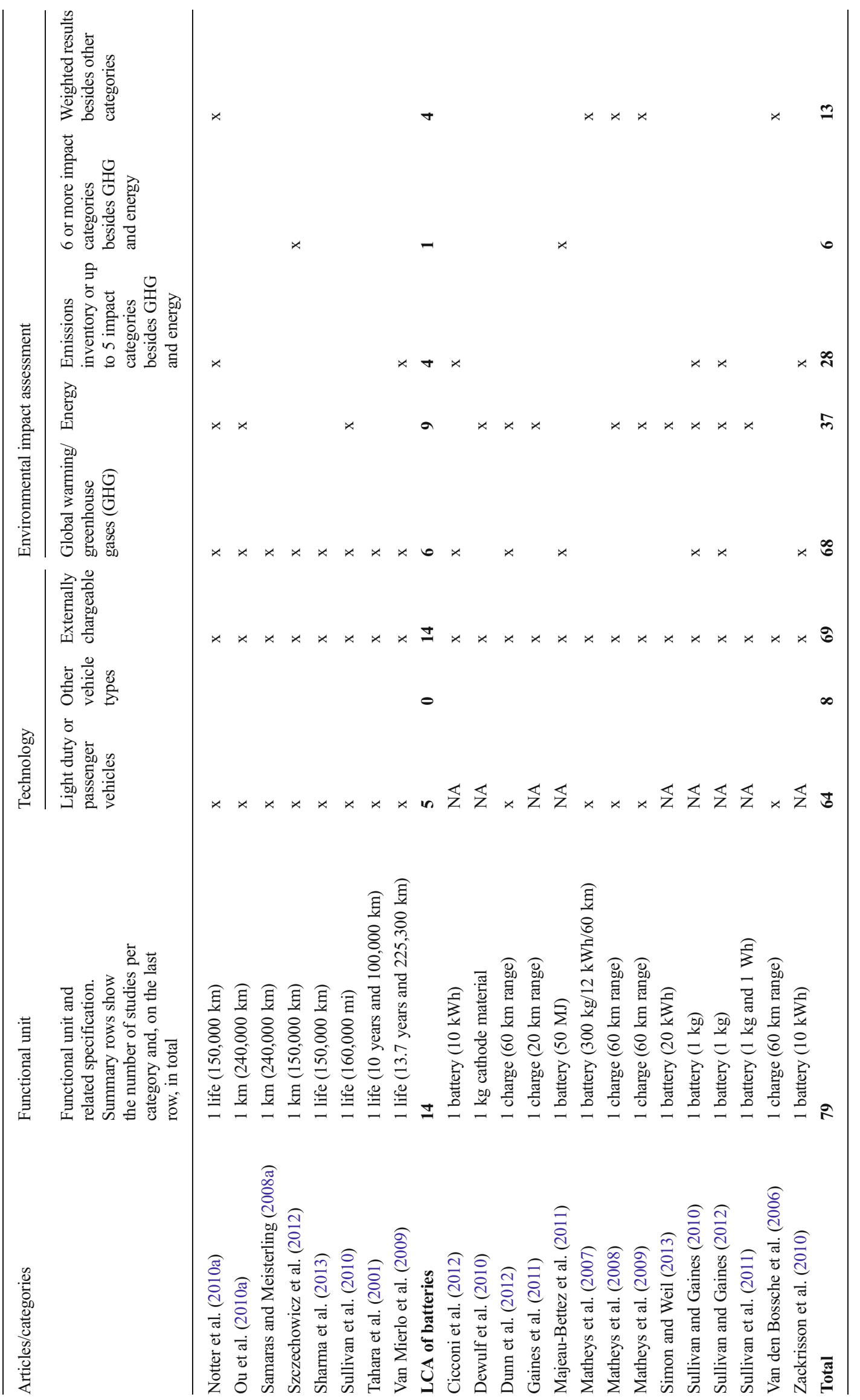




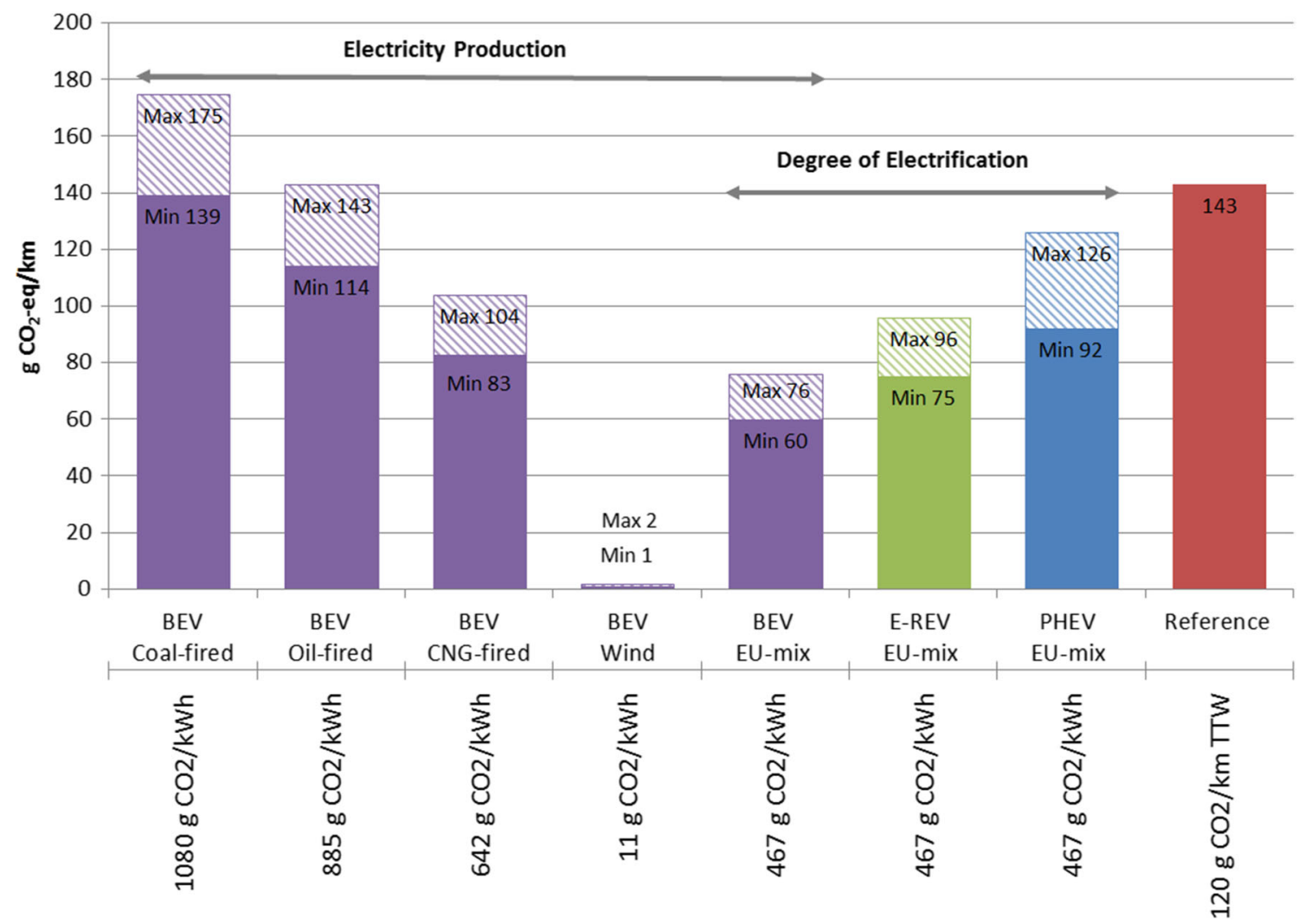

Fig. 2 WTW GHG emissions for different electricity production and degrees of electrification. To the right, BEV, E-REV, and PHEV values using the EU average electricity mix of 2008 (467 g CO2-eq./kWh), according to Edwards et al. (2011b). To the left, BEV data has been

The reference vehicle in Fig. 2 corresponds to a former fleet target value suggested by the European Parliament for new sales in $\mathrm{EU}$ of $120 \mathrm{~g} \mathrm{CO}_{2}$-eq. $/ \mathrm{km}$, later rephrased to a mandatory fleet value of $130 \mathrm{~g} \mathrm{CO}_{2}$-eq./km by 2015 (for the type approval and per manufacturer) (European Parliament 2008). However, typical average values for family-sized cars on the road in Belgium today are above $200 \mathrm{~g} \mathrm{CO}_{2}$-eq./km (Messagie et al. 2010). This difference emphasizes the importance of selecting a reference object in line with the study goal and time perspective. The formulation of the functional unit is closely related. It is a reference unit used to quantify all studied alternatives in a comparison on equal basis. As shown in Table 2, almost all WTW results are presented in relation to the unit "kilometers of driving" (or "miles of driving") which suggests all evaluated WTW studies use exactly the same basis of comparison. Other quantifiable differences, such as seat numbers and load capacity, as well as non-quantifiable functions, for example comfort, safety aspects, and the role of vehicles as status symbols, are then disregarded.

\subsubsection{Driving modes}

WTW studies can also be used to assess the impacts of different modes of operation. Typically, this could be the recalculated for different types of electricity production (Dones et al. 2007). The reference vehicle corresponds to the $2012 \mathrm{EU}$ fleet target for tailpipe emissions of sold cars (European Parliament 2008). For detailed information, see Electronic Supplementary Material

impact of different driving styles, traffic situations and powertrain control strategies governed by software. Figure 3 shows an example of such a WTW study, which examines the GHG emissions of a conventional petrol vehicle compared to a HEV and a PHEV operating in different traffic conditions (Raykin et al. 2012). The study is limited to large family cars with similar specifications. The results for three driving modes are shown. City driving refers to slow driving with many starts and stops in highly congested traffic. Suburban driving refers to a scenario with less congestion, allowing for higher speeds. Highway driving refers to high speeds and no stops. Results show that hybridized powertrains are beneficial in congested traffic where the many stops allow for regenerative breaking to recover energy. In addition, at standstill, conventional vehicle engines are kept idling whereas hybridized vehicles automatically turn off (Kobayashi et al. 2009).

\subsubsection{Meta-analysis of learnings from well-to-wheels studies}

Table 3 shows the results of the qualitative meta-analysis conducted on all included WTW studies. Three topics were identified - influence of the supplied electricity for charging, degree of electrification, and mode of operation - and it can be concluded that a vast majority of the WTW studies 
Fig. 3 WTW GHG emissions for three large family vehicles with different degrees of electrification in three different traffic situations according to Raykin et al. (2012). Electricity is assumed to be produced from natural gas and all vehicles use petrol. For detailed information, see Electronic Supplementary Material

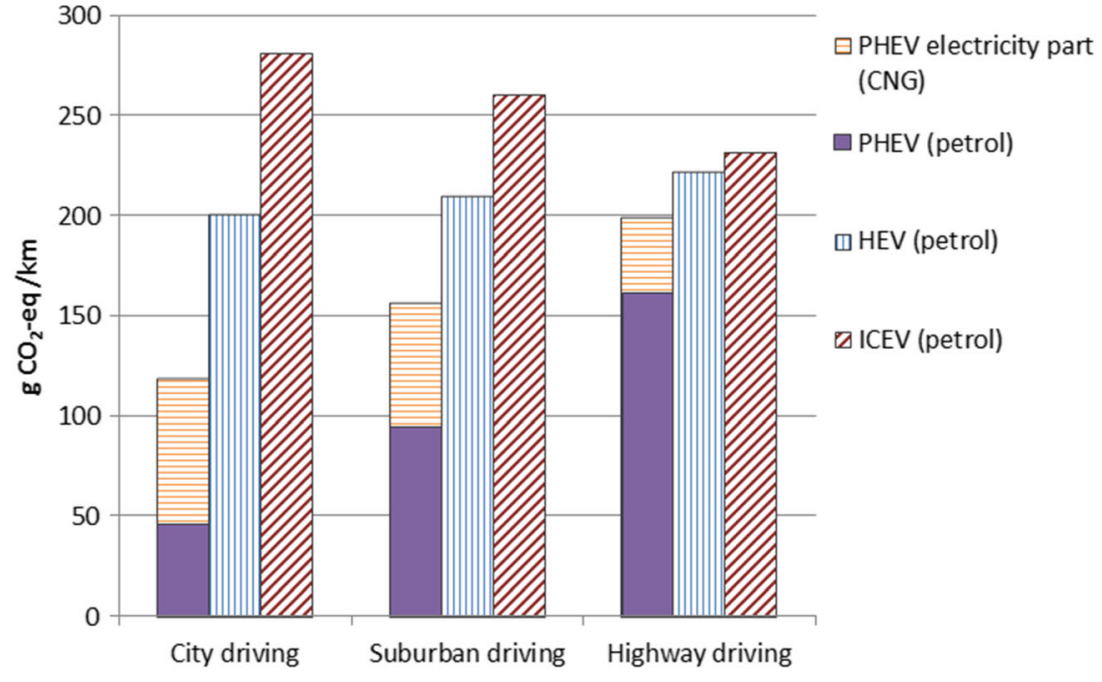

support that all three are key factors for the outcome of the results. In addition, none of the reviewed studies point out any of the factors as unimportant. In the case of electricity production, all studies including chargeable vehicles were included.

WTW studies link production of various energy carriers to different emissions, and then to how efficiently energy carriers are converted to transportation work within different vehicle types. The energy use and efficiency are dependent on the vehicle size along with the degree of electrification and mode of operation. However, in some cases, WTW studies provide insufficient information. For example, when results are presented for BEVs charged with electricity with low GHG emissions. WTW studies might give the impression such vehicles have almost no environmental burden at all. This is untrue. Another case is WTW studies used to compare climate impacts of vehicles in very diverse segments. In both cases, it can be argued that a complete LCA is more appropriate.

5.3 What can we learn by including the equipment life cycle?

\subsubsection{Complete LCA}

Including both the WTW life cycle and the equipment life cycle as part of a complete LCA can provide a more comprehensive

Table 3 Summary of a qualitative meta-analysis conducted on all included WTW studies. For detailed information, see Electronic Supplementary Material

Share of studies, when covering the topic, which report that the...

\begin{tabular}{ll}
\hline .. supplied electricity for charging is a key factor for the results & $87 \%$ \\
... degree of electrification is a key factor for the results & $78 \%$ \\
... mode of operation is a key factor for the results & $100 \%$ \\
\hline
\end{tabular}

mapping of vehicles' environmental impact. This allows comparison between vehicles of different sizes, as powertrain composition is included in the assessment. Complete LCA is also suitable to assess the balance between the electric part and the conventional part of the powertrain in a PHEV, e.g., different allelectric range depending on the battery. Figure 4 shows an example of overall lifetime GHG emissions per kilometer for 13 ICEVs and 3 electrified vehicles in four different segments. Data is based on NEDC-certified fuel consumption rates (Van Mierlo et al. 2009) and average EU electricity mix for 2008 for the BEV. As expected, larger vehicles generally have higher emissions. Notable is that HEVs have low emissions within their segments and that the small family-sized BEV has the lowest lifetime GHG emissions, including in comparison to the smaller city segment.

A general rule of thumb may be established from the results of the complete life cycle studies in Table 2-the WTW life cycle dominates with regard to energy use, both for ICEVs and those with electrified powertrains. However, many studies show the relative importance of the manufacturing stages increases with electrification. This is due to the reduction of emissions from the WTW life cycle and the introduction of new components. For example, one reviewed study of light passenger vehicles indicates that GHG emissions of BEVs can come in approximately equal shares from the WTW life cycle of the energy carrier and the equipment life cycle of the vehicle (Ma et al. 2012). More specifically, this result refers to a BEV driven in urban conditions without load and charged with a projected average grid mix in the UK (450 g CO 2 -eq. $/ \mathrm{kWh})$. But the WTW share of total GHG emissions dominates as soon as more fossil-intense electricity is considered or the driving scenario is set to highway or suburban because then energy consumption per driven kilometer increases. Another study shows the equilibrium point between the WTW and equipment life cycles varies in different countries because of 


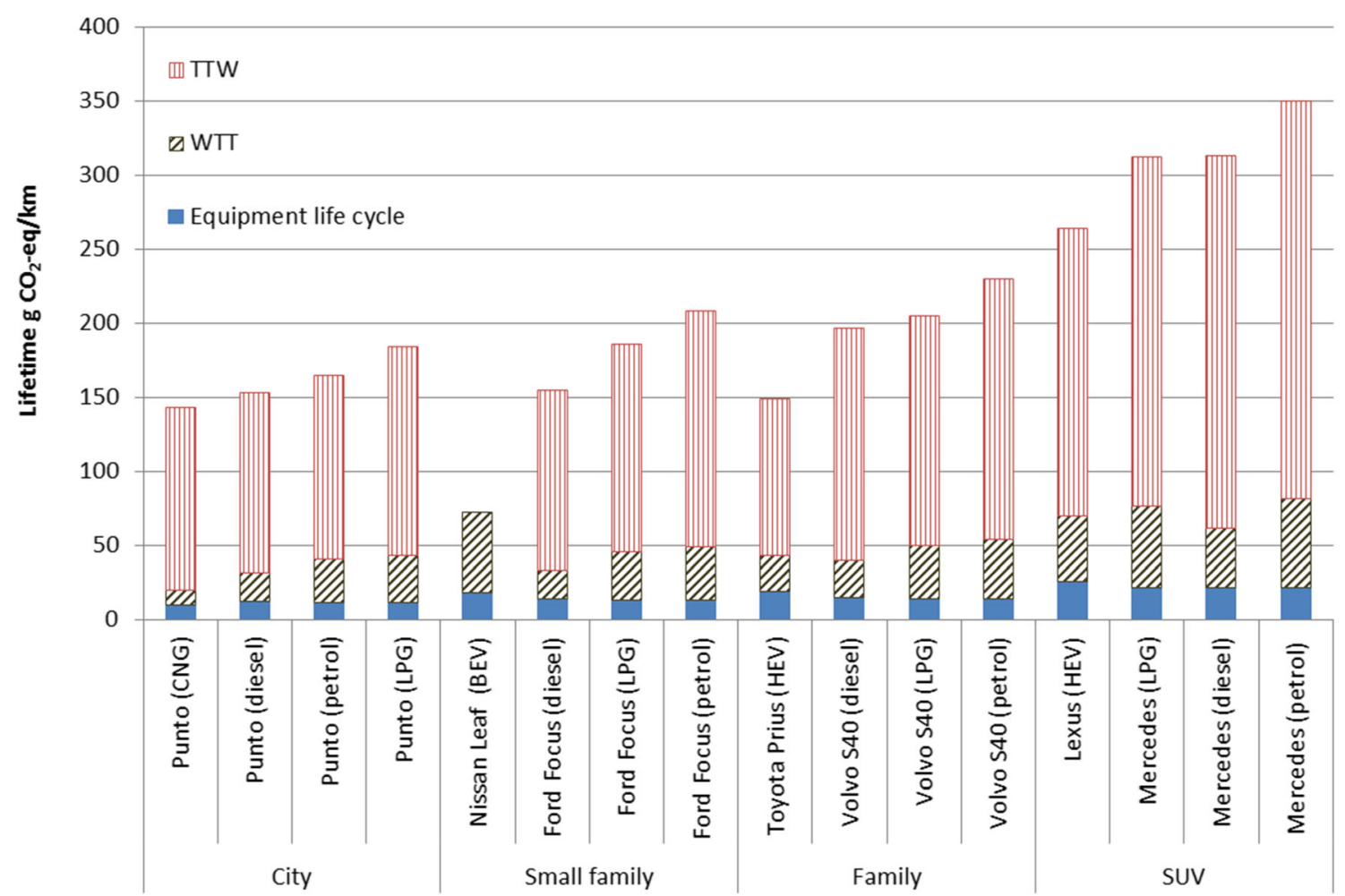

Fig. 4 Passenger cars divided into typical segments (Belgian Ecoscore classification) showing the general trend in $\mathrm{CO}_{2}$-emissions for the complete life cycle divided into WTT, TTW, and equipment life cycle based on the CLEVER study (Van Mierlo et al. 2009). An average vehicle lifetime of $230,500 \mathrm{~km}$ corresponding to 13.7 years has been used, based

different electricity mixes, but that BEVs and PHEVs always increase their benefits compared to ICEVs, the longer they are driven during their lifetime (Nonaka and Nakano 2010).

\subsubsection{Energy demand of material production and equipment manufacturing}

Obviously, a main element in the equipment life cycle of electrified vehicles is the energy necessary for the first two stages: material production and manufacturing of parts. Results for vehicles in the compact class with present technology and manufacturing procedures can be found in, for example, Notter et al. (2010a). This paper presents the cumulative energy demand and GHG emissions for one BEV and one ICEV version of the same type of car, comparable to a Volkswagen Golf in size and power. They find that manufacturing of the BEV demands around $120 \mathrm{GJ}$ compared to $94 \mathrm{GJ}$ for the ICEV (Notter et al. 2010b). Assuming, as in the study, a 150,000 km lifetime gives 46 and $35 \mathrm{~g} \mathrm{CO}_{2}$-eq./ $/ \mathrm{km}$, respectively, in terms of GHG emissions. For the BEV, the base vehicle (i.e., excluding the powertrain) accounts for $54 \%$ of these emissions, the lithium-ion battery for $26 \%$, and the remainder of electric powertrain for $20 \%$. The energy use in the production stages derives from several different types of processes, such as use of natural gas in industrial furnace, use of electricity (in this case on statistical data from the Belgian vehicle registration database. Fuel consumption is based on NEDC data. The Nissan Leaf BEV has been assumed to be charged with EU-mix electricity. For detailed information, see Electronic Supplementary Material

European UCTE mix of $596 \mathrm{~g} \mathrm{CO}_{2}$-eq./kWh), and combustion of diesel in transportation (Notter et al. 2010b).

Slightly higher values are presented in some other studies. Samaras and Meisterling (2008a) find that for PHEVs in same segment with all-electric ranges of 30 to $90 \mathrm{~km}$, the values span from 113 to $136 \mathrm{GJ}$ per vehicle. This is coupled to GHG emissions of $62-73 \mathrm{~g} \mathrm{CO}_{2}$-eq. $/ \mathrm{km}$ when recalculated with a $150,000 \mathrm{~km}$ lifetime for comparison $(240,000 \mathrm{~km}$ was used in the study). However, out of this, the manufacturing of the base vehicle represents as much as $102 \mathrm{GJ}$. Also, the main share of energy is electricity based on a relatively carbon-intensive US average grid mix (Samaras and Meisterling 2008b).

Some of the highest values for energy demand in equipment manufacturing has been shown by Hawkins et al. (2013a, b), reporting 72-81 $\mathrm{g} \mathrm{CO}_{2}$-eq. $/ \mathrm{km}$ for a compact-sized BEV (150,000 km lifetime). Battery manufacturing, based on a study by Majeau-Bettez et al. (2011), is pointed out as an important explanation. Actually, Dunn et al. (2012) have investigated the difference between the values reported by Majeau-Bettez et al. (2011) and Notter et al. (2010a), and observed that the energy used to manufacture specific battery subcomponents is more than 1 order of magnitude larger in the study by Majeau-Bettez et al. In trying to explain the cause, Dunn et al. (2012) found that studies which use a more detailed "process level" approach to the life cycle inventory, as Notter el al., produce much lower values 
for equipment life cycle of the battery, compared to a higher level "top-down" approach used by Majeau-Bettez et al. Finally, Dunn et al. (2012) argue that the process level approach is more accurate and presents results similar to those of Notter et al. for the overall battery manufacturing energy demand.

\subsubsection{Functional unit}

In general, the functional unit of complete LCAs is defined as a "vehicle life" specified by a total number of driven kilometers, as shown by Table 2. It can be observed that assumed life lengths vary largely, both in terms of total driving distance and years of operation. One reason for this is that different segments are considered. However, a key reason for conducting a complete LCA instead of a WTW study is to effect comparison between different sized vehicles. A common total drive distance is often stipulated, although in reality there might be differences between study objects. One way to approach this is to use some type of fleet average, as in Fig. 4. Nevertheless, the assumptions made for the total amount of kilometers driven are very important to the outcome of the study and the choice of functional unit in complete LCA calls for extra attention. Several reviewed studies which include the equipment life cycle have " $1 \mathrm{~km}$ " or some other trip distance as the selected functional unit. The calculated contribution to the environmental impact of the equipment will vary with the assumption for lifetime driven distance. As an example of how this can affect results, the numerical results for GHG emissions previously presented in section 5.3.2, with a 150,000-km stipulated distance, has been summarized in Table 4 . It is also shown how the results change if instead $250,000 \mathrm{~km}$ is assumed. As it can be observed, when assuming a short lifetime driven distance, the impact of the equipment life cycle becomes higher in the LCA end results.

\subsubsection{Meta-analysis of learnings from equipment life cycle studies}

The qualitative analysis carried out on all complete LCA studies is presented in Table 5. It shows the share of studies that report the WTW stage to dominate over equipment life cycle of electrified vehicles in terms of energy, the impact of the equipment life cycle to increase with electrification, and the battery as the

Table 4 Sensitivity of equipment life cycle GHG emissions to the lifetime driven distance, when presented per kilometer. For detailed information, see Electronic Supplementary Material

\begin{tabular}{|c|c|c|}
\hline Original study & $150,000 \mathrm{~km}$ & $250,000 \mathrm{~km}$ \\
\hline Notter et al. (2010a) & $46 \mathrm{~g} \mathrm{CO}_{2}$-eq. $/ \mathrm{km}$ & $28 \mathrm{~g} \mathrm{CO}_{2}$-eq. $/ \mathrm{km}$ \\
\hline $\begin{array}{l}\text { Samaras and Meisterling } \\
\text { (2008a) }\end{array}$ & $62-73 \mathrm{~g} \mathrm{CO}_{2}$-eq. $/ \mathrm{km}$ & $37-44 \mathrm{~g} \mathrm{CO}_{2}$-eq./km \\
\hline Hawkins et al. (2013b) & $72-81 \mathrm{~g} \mathrm{CO}_{2}$-eq. $/ \mathrm{km}$ & $43-49 \mathrm{~g} \mathrm{CO}_{2}$-eq. $/ \mathrm{km}$ \\
\hline
\end{tabular}

Table 5 Summary of a qualitative meta-analysis conducted on all equipment life cycle studies, i.e., sorted under "complete life cycle" in Table 2. For detailed information, see Electronic Supplementary Material

Share of studies, when covering the topic, which report that the...

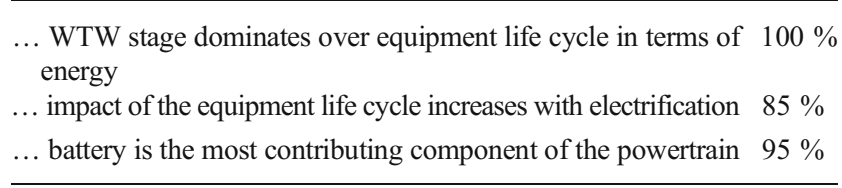

most contributing component of the powertrain. All three statements are clearly supported by the literature which covers the topic. As regards the impact of the equipment life cycle, clear evidence has not been found in some cases, neither for an increase nor a decrease. However, one study finds that all impacts decrease with electrification, for a non-road agricultural vehicle (Mousazadeh et al. 2009). Andrews (2006) is the only study which reports that the "intelligent power unit" contributes more than the battery to the overall environmental impact.

By adding the equipment and WTW life cycles, a more complete assessment is achieved. This is necessary when vehicles with similar WTW performance but in different segments, or with different degrees of equipment complexity, are compared. As long as fossil fuels are used for electricity production and propelling ICEVs, the WTW stage will play a dominating role for the emission of GHG. Keys to improvement of environmental performance will then be to minimize the demand for fossil fuels in the WTT stage and to increase efficiency in the TTW stage. The addition of the equipment life cycle provides information about the roles of the different components and the effects of changes in the powertrain. It can clearly be observed that GHG intensity of the equipment manufacturing is coupled to the amount of fossil energy present in both the electricity supply as well as in industrial processes. The manufacturing of the battery, and the preceding material production, are main drivers of energy use in production of electrified vehicles. Still, production of other electric powertrain components also demands energy with notable contributions to GHG emissions. But, regarding the meta-analysis result for the most contributing component, it can be noted that Andrews (2006) takes more environmental aspects into consideration than emissions of GHG. A more comprehensive description of the environmental performance of electrified vehicles thus requires the scope of environmental impact to be broadened.

5.4 What can we learn from a broader impact assessment?

\subsubsection{General description of LCIA}

So far, we have mainly discussed emissions of GHG connected to the use of energy in operation and manufacturing. However, there are other resources and emissions which are relevant. For a life cycle assessment to be regarded as extensive and complete, it should cover impacts on three important areas of protection: 
natural environment, natural resources, and human health (ISO 2006a).

LCA results can be presented in different formats. For example, the inventory format (detailed resource use and emissions) is useful when the target audience is well informed about the substances emitted from the life cycle in focus. This is the case in the automotive industry with regulated tailpipe emissions additional to carbon dioxide - carbon monoxide (CO), unburned hydrocarbons (HC/VOC), nitrogen oxides $\left(\mathrm{NO}_{x}\right)$, and particulate matter $(\mathrm{PM})$. There are also numerous other substance flows, including resources and non-regulated emissions, and this is why LCIA is often conducted. LCIA aggregates emissions contributing to the same type of environmental effect into one indicator per impact category, e.g., climate change, eutrophication, and human toxicity, and likewise for resource use, e.g., land use and resource depletion. By means of weighting, further aggregation can be achieved all the way to one single number: a one-dimensional measure of environmental impact. However, whatever weighting method is used, it will include a large number of contested value judgments. Therefore, LCIA is often stopped at characterization, where inventory results are aggregated into a limited number of impact categories using models based on natural science.

\subsubsection{Airborne pollutants}

A typical impact category is the frequently shown global warming potential (GWP), reporting all GHGs as $\mathrm{CO}_{2}$-equivalents. Another is photo-oxidant creation potential (POCP), which indicates how local air pollutants $\left(\mathrm{NO}_{x}\right.$ and unburned hydrocarbons) build up smog under the influence of sunlight and harm both health and growing crops. Eutrophication potential (EP) covers the effect of macronutrients in soil and water (including $\mathrm{NO}_{x}$ ). Acidification potential (AP) indicates the potential environmental impact of acidifying substances such as $\mathrm{NO}_{x}$ and sulfur oxides $\left(\mathrm{SO}_{x}\right)$.

Figure 5 shows examples of LCA results presented as LCIA indicators for eutrophication and acidification from two different studies, both based on the same Belgian vehicle database as those shown in Fig. 4, but with the Belgian electricity mix (studies with a common underlying dataset were chosen in order to be able to combine them) (Boureima et al. 2012; Messagie et al. 2010). A BEV and a HEV in the small family-size segment are compared with two ICEV references. As can be seen, the impact is lowest for the fully electric vehicle in both impact categories, just as in the case of GHG emissions in Fig. 4. The explanation is a covariance for all categories relating to airborne pollutants, mainly caused by combustion in the vehicle or at a power plant. Consequently, results for externally chargeable vehicles in any of these categories are strongly dependent on the pollution status of the electricity production and the overall efficiency of the WTW life cycle.

\subsubsection{Resource use}

Indicators discussed so far relate to emissions of pollutants. However, LCA aspires to include resource use. Use of abiotic resources may be aggregated into one indicator for abiotic resource depletion potential (ADP), often expressed in terms of antimony equivalents (kg Sb-eq.). It covers non-living resources such as metals and oil (Guinée

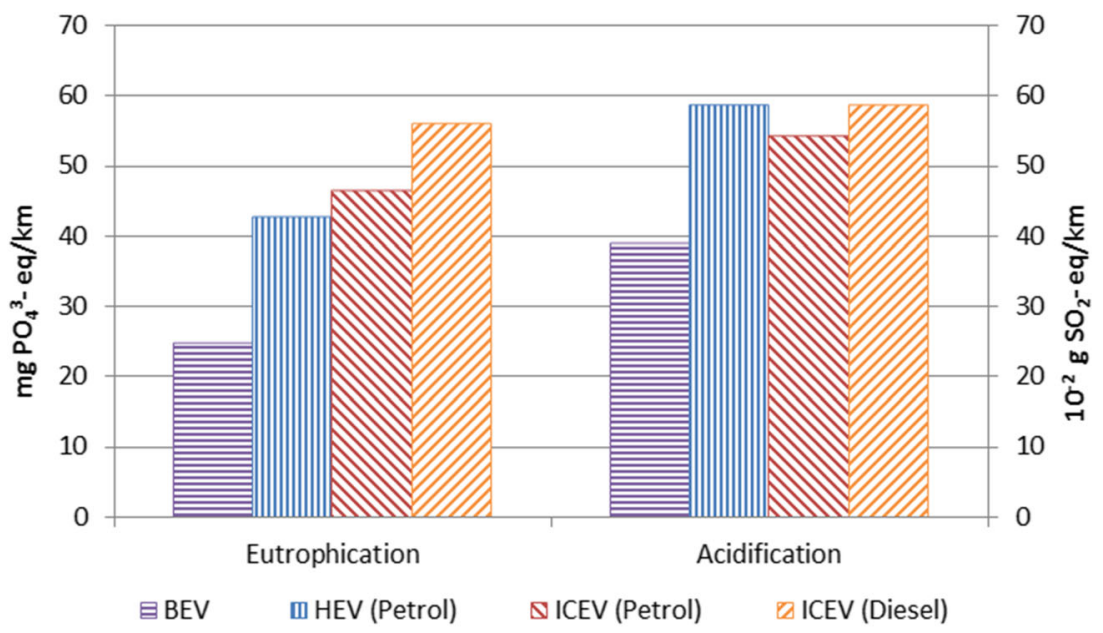

Fig. 5 Results for eutrophication (left) and acidification (right) impact categories in an LCA of family vehicles in Belgium (Messagie et al. 2010; Boureima et al. 2012). The BEV is equipped with a lithium ion battery assumed to be charged with the Belgian electricity mix for 2007 (roughly half nuclear, one third fossil, and one sixth imported energy) (Dones et al. 2007). The HEV has a NiMH battery

and a Euro 4 emission standard engine. The reason that HEV have slightly higher values for acidification than the petrol ICEV is that the production of nickel for the NiMH battery emits acidifying substances. ICEV references for petrol and diesel are both Euro 5 standard. For detailed information, see Electronic Supplementary Material 
et al. 2002). In Notter et al. (2010a), ADP was presented for two different versions of a vehicle in the compact class: an ICEV and a BEV. According to the study, total results were around $260 \mathrm{~kg} \mathrm{Sb}$-eq./vehicle life (26\% equipment cycle and $74 \%$ WTW cycle) for the ICEV and $190 \mathrm{~kg} \mathrm{Sb}-$ eq./vehicle life (41\% equipment cycle and $59 \%$ WTW cycle) for the BEV. The BEV uses up more metal resources in its equipment cycle than the ICEV, while the latter uses more fossil energy. However, underlying ADP characterization factors used in this example are based on extraction rates now 10-15 years old (Guinée et al. 2002; Schneider et al. 2011). As a consequence, high scores are given for fossil energy depletion in comparison to copper, nickel, lithium, and rare earth metals relevant for electric and hybrid vehicles. More recent, frequently used LCIA resource use indicators, for example ReCiPe2008, would have placed more weight on copper and nickel (Goedkoop et al. 2012). Also, materials which currently play a key role in vehicle electrification, such as lithium and rare earth metals, are not covered by any of the easily available LCIA methods (Goedkoop et al. 2012; Goedkoop and Spriensma 2001; Jolliet et al. 2003).

\subsubsection{Toxicity and mining}

Local emissions of toxic substances from the manufacturing stages are an environmental aspect brought up by Hawkins et al. (2013a) as a possible disadvantage of electric powertrains, and especially in connection to battery production. Few other studies in Table 2 include the human toxicity potential (HTP), and to broaden the analysis of the topic, Fig. 6 presents our own results (Messagie 2013) for HTP in units of 1,4-dichlorobenzene (DCB) equivalents, a well-known pesticide. Our results confirm the earlier work of Hawkins et al. (2013a) and indicate significantly higher impact from BEVs than ICEVs with respect to toxicity. The largest impact comes from the equipment cycle of the non-powertrain parts (base vehicle) for both the BEV and the ICEVs. But in the case of the BEV, the components specific to the electric powertrain (Li-ion battery, electric motor and power electronics) together cause close to half of the overall impact ( $44 \%$ in this specific case). In the ICEVs, the small electric starter motor and catalytic converters in the conventional propulsion system have an important impact.

Mining processes are an important explanation for HTP results in Fig. 6. Excavation is required for metal production as well as nuclear and fossil electricity. Material processing is especially energy intensive, and leakage from the waste disposal of mining spoils of nuclear and hard coal energy contributes to toxicity (Dones et al. 2007). High use of copper and nickel, in batteries and electric motors, and copper and gold, in power electronics, increase disposal of mine tailings containing sulfides (Classen et al. 2009). Consequently, improved waste handling in the mining industry and a less coaldependent energy mix could dramatically change these results and decrease the environmental load of BEVs.

Toxicity impact categories (human toxicity and various types of ecological toxicity) are complicated (Finnveden et al. 2009) and relate to many different substances and their inherent toxicity, along with potentials to which humans and ecosystems are exposed in a manner that cause adverse effects (Huijbregts et al. 2000). HTP describes environmental persistence and accumulation in the food chain. Data is derived from test data from humans or laboratory animals, in which interspecies conversion factors are assumed. Such dependence on various background conditions and the need for very large data sets in assessments generally couple this impact category to a high degree of uncertainty (Finnveden et al. 2009).
Fig. 6 Results for human toxicity potential comparing compact class vehicles for different powertrain options (Messagie 2013). For calculation of WTW life cycle values for the BEV, a vehicle life distance of 209,470 km charged with 2011 Belgian electricity mix has been assumed. All petrol and diesel are Euro 5 standard. For detailed information, see Electronic Supplementary Material

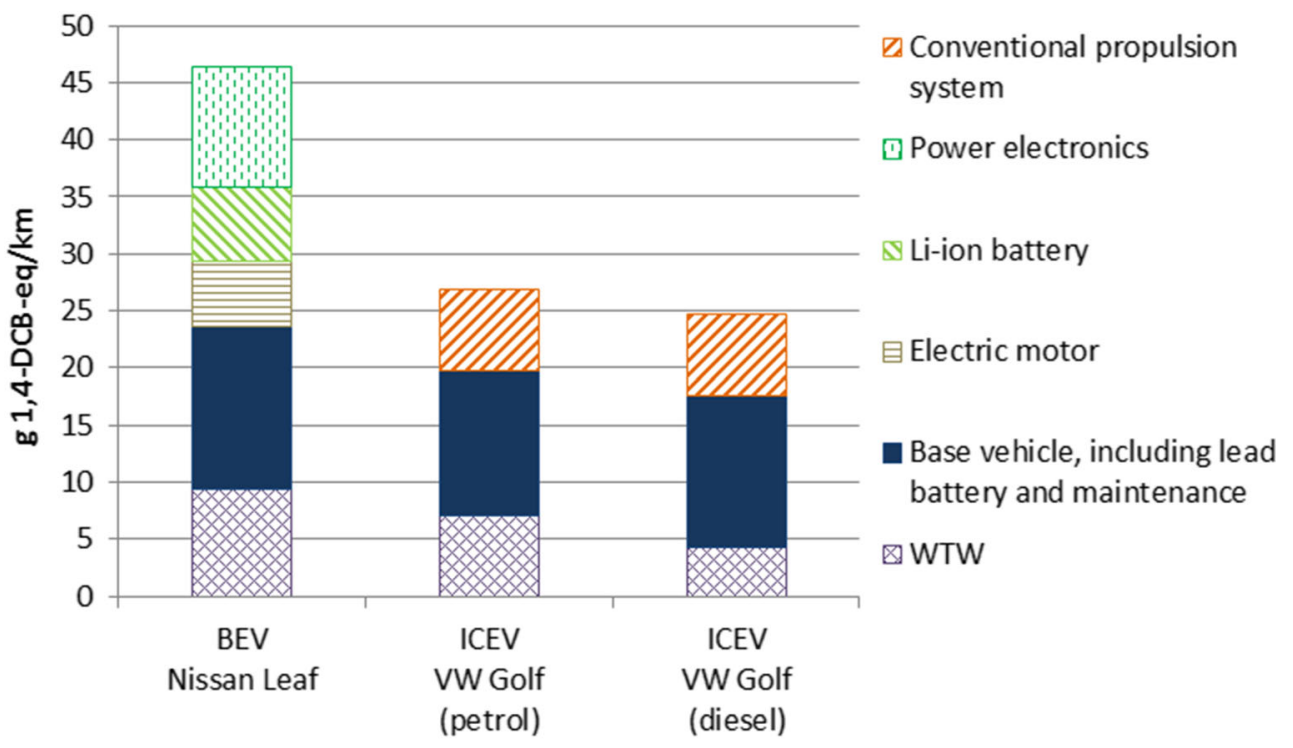


However, the results in Fig. 6 can be put in perspective. Human toxicity is not the only contributor to damage to human health (Goedkoop et al. 2012): global warming, particulate matter formation, photochemical oxidant formation, ozone depletion, and ionizing radiation also contribute. Using for example ReCiPe2008 (Goedkoop et al. 2012), climate change as a consequence of global warming contributes most to human health damage caused by vehicles. This is followed by human toxicity and effects of particulate matter. Calculated this way, the petrol and diesel vehicles in Fig. 6 thus have a larger impact on human health than the BEV.

\subsubsection{Weighted results for batteries and recycling}

So far, mainly studies modeling the entire vehicle have been described. As pointed out earlier, it is quite common to focus on the battery. Figure 7 shows LCA results for different battery types for a fully electric compact car aggregated to a single score according to the panel-based weighting system, Eco-indicator'99 (Van den Bossche et al. 2006). Different impact categories are weighted based on societal values and summed up to analyze the trade-off between benefits in several impact categories and drawbacks in others. It shows that high-energy density and low system losses of lithium-ion and sodium-nickel chloride technologies are rewarded with low scores. The difference between "with" and "without recycling" shows that modeling assumptions about the recycling are very important to the results for all battery types. High collection rates and that almost all material is recovered to virgin quality have been assumed (Van den Bossche et al. 2006). The potential for such recycling of lithium-ion batteries, which is both energy efficient and has high recovery rate, has been investigated in several papers (Dunn et al. 2012;
Gaines et al. 2011; Li et al. 2013; Sullivan et al. 2011). However, only in the case of lead acid batteries are highly efficient recycling processes currently in practice. For newer technologies, this means an entirely new and large-scale recycling industry must be put in place if these results are to be realized (National Research Council 2013). In 2005 still, the recycling rates of important included specialty metals such as rare earths and lithium were less than $1 \%$ globally.

Additionally, battery technology is progressing very rapidly and data for environmental performance outdates quickly. In LCA studies conducted around 2005, it was common to assume one or even two battery replacements over an average vehicle lifetime. Today it is often argued that the battery will last as long as the vehicle (Zackrisson et al. 2010). Also, critical steps in manufacturing have been improved. Furthermore, technology development changes which battery types are considered relevant and included in the study, which can be observed in the reviewed literature.

Finally, as noted above, weighting methods are based on value judgments and can be very different depending on the stakeholder. For this reason, the ISO standard (ISO 2006b) recommends that LCA studies which use single scoring include several different weighting factors and weighting methods, and that sensitivity analysis is conducted to assess the consequences of the LCIA results of different valuechoices.

\subsubsection{Meta-analysis of learnings from a broader LCIA}

The qualitative meta-analysis conducted on studies with broader LCIA scope than GHG emissions and energy demand, with results shown in Table 6, demonstrates two main observations, i.e., that few studies assess resource depletion

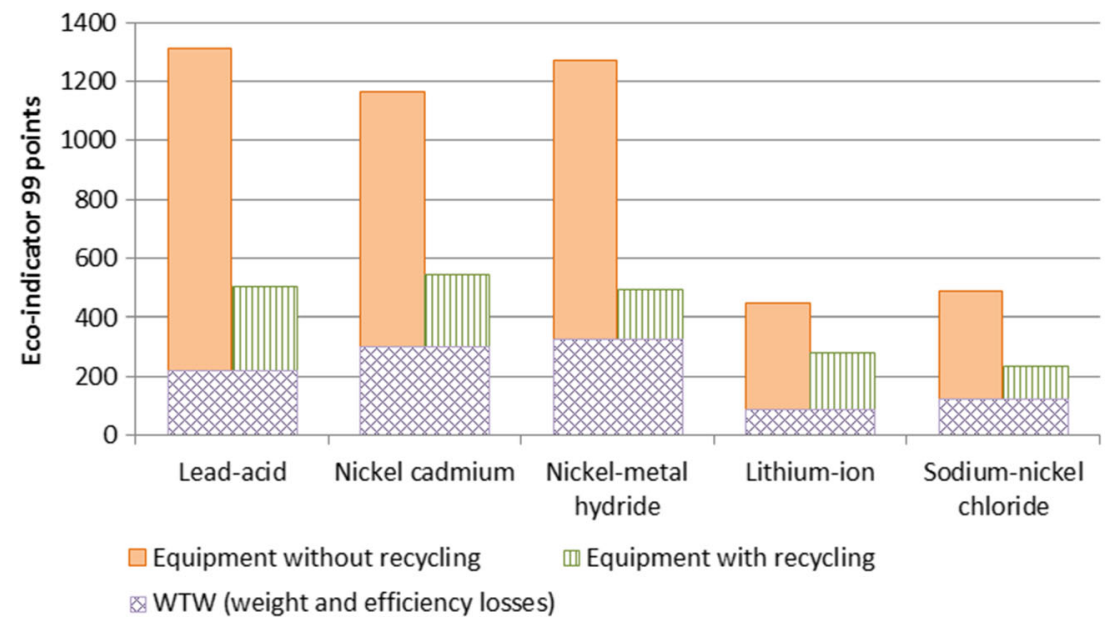

Fig. 7 Eco-indicator'99 results with and without highly efficient recycling for the environmental score of different battery types-all dimensioned to provide $60 \mathrm{~km}$ range at an $80 \%$ depth of discharge for an $888 \mathrm{~kg}$ electric car (excluding the weight of the battery) and a vehicle life distance of $180000 \mathrm{~km}$ with 3,000 charge-discharge cycles. The
WTW stage corresponds to the amount of European mix electricity needed to cover internal losses and carry the weight of the battery itself (Van den Bossche et al. 2006). For detailed information, see Electronic Supplementary Material 
Table 6 Summary of a qualitative meta-analysis conducted on all equipment life cycle studies and battery component LCA studies, i.e., sorted under "complete life cycle" or "LCA of batteries" in Table 2. For detailed information, see Electronic Supplementary Material

Share of studies which report...

\begin{tabular}{l}
\hline$\ldots$ resource use of the equipment life cycle as a part of the \\
assessment \\
$\ldots$ that recycling is a key factor for the result, if the topic is \\
covered
\end{tabular}

and that recycling is a key factor for the environmental impact. It included all studies in Table 2 considering the equipment life cycle, both on component and vehicle level, namely both complete vehicle LCAs and battery LCAs. As regards recycling, those that present results for different rates of recycling in the end-of-life scenarios were deemed to cover the topic. Only seven studies were found to investigate resource use. Three (Bartolozzi et al. 2013; Notter et al. 2010a; Szczechowicz et al. 2012) use CML's (Guinée et al. 2002) abiotic resource depletion category, two (Hawkins et al. 2013a; Majeau-Bettez et al. 2011) use ReCiPe2008 (Goedkoop et al. 2012), one (Andrews 2006) uses Ecoindicator'99 (Goedkoop and Spriensma 2001), and one (Lave et al. 2000) presents and discusses inventory results.

Impact assessment beyond GHG can be conducted to very different degrees, from a couple of selected additional emissions in inventory format to more than ten different aggregated impact categories or, even further, to a weighted single score result. Different categories provide information for different stakeholders, i.e., the intended audience is very important when selecting which categories to include in a study. However, with regard to emissions of airborne pollutants, the value for GHG is generally a good overall indicator for all related impact categories.

In contrast, impact categories related to resource extraction, such as abiotic resource depletion and human toxicity, provide new information. But, such impact categories are complicated, highly uncertain, and do not always consider all relevant aspects, for example rare earth metals in the case of ADP. For a more thorough evaluation of all different LCIA methods discussed in this paper, please see Hauschild et al. (2013).

\section{Learnings and conclusions}

\subsection{Methodological learnings}

The numerical results presented by any LCA study are particular to the given context and study format. At the same time, LCA can be used to address many different questions using varying technical and methodological scope. The ISO standard states that "the depth of detail and time frame of an LCA may vary to a large extent, depending on the goal and scope definition" (ISO 2006a). However, as shown, most LCA studies in Table 2 do not have comprehensive purpose declaration. The motive for key assumptions and limitations thereby becomes non-transparent, and general conclusions might appear to be drawn without foundation. Our impression is that the discussion is then easily caught up in the details of numerical results and, as a consequence, important lessons from the research field are overshadowed by an appearance of complexity and diverging outcome. Also, without a clearly stated and motivated goal, it becomes difficult to critically evaluate the appropriateness of the selected scope and data sets. As a solution, we argue that a clear definition of both goal and scope has to be presented in all studies, to provide context and basis for conclusions (ISO 2006a). For example, the functional unit shapes the format of the end results and is decisive to their interpretation. It often includes assumptions about the lifetime driven kilometers of the studied vehicles. Both low and high estimates can be valid, and thus it is not enough to solely state the selected functional unit. A clear and thorough motivation is required, directly linked to the purpose of the study.

Another important methodological aspect is time. The majority of all reviewed studies do not report the time scope, a crucial motive for the selection of data and significant for the universality of the conclusions. Additionally, the review shows that most assessments focus on the performance of today's electric vehicle technology used in today's electricity production system, although both vehicle technology and electricity production can be expected to have changed considerably before electric vehicle volumes become comparable to those of ICEVs. Nonetheless, many studies consider the sensitivity of their results to different electricity production mixes in the background energy system, both geographically and methodologically (average/marginal). But such sensitivity analysis is not often coupled to a discussion about improvements or development over time. Sometimes, improved component design is subject to sensitivity analysis, for example increased battery life length, but benefits of scale in material processing and manufacturing are rarely explored.

As an emerging technology, electric propulsion of road vehicles cannot be expected to yet have reached the level of maturity or scale of production for which it shows potential (Sandén 2008). It can then be argued it is equally important to examine the environmental performance of future states, in which the technology has reached its full potential, as the current state of development (Hillman and Sanden 2008). But, the use of future scenarios introduces uncertainty. As a solution, different stylized scenarios can be used to reflect relevant options for technical and societal change. Such scenarios must not likely become reality. Instead, they are selected to show inherent properties of the technology. In such a setup, LCA can be regarded as a learning tool for strategic assessments of a technology, with the main aim of identifying 
key improvement areas and potential showstoppers in order to guide development towards a desired future.

Conversely, if the aim is to explore technology in present time, there are still many aspects of uncertainty to deal with. Hawkins et al. (2012) promote more detailed LCIs, which is a part solution. But data may be both inherently variable and very difficult to obtain with high precision; for example in the configuration of a powertrain or the technical design of a specific component. Parameter uncertainty analysis using mathematical error propagation methods can then be used, if sufficient amount of data to provide statistical distributions is available. Several of the reviewed references conduct parameter uncertainty analysis. However, some parameters are then not covered, for example, most LCIA characterizations factors. There are also methodological uncertainties in selecting which technologies to assess, how to draw system boundaries, and when making necessary simplifications and assumptions. A well-formulated goal and scope definition decreases such model uncertainties, but cannot remove them. High recycling rates are an example, and they are assumed although vehicle end-of-life generally is not well mapped and effective recycling of every material, to high quality products, is far from being achieved (Graedel et al. 2011). For these reasons, we find it important to always test the robustness of results in any study and to take this into account when giving recommendations. With so many uncertainties, it becomes irrelevant to strive for very high precision in results. Instead, robust lessons which hold for sensitivity analysis may be sought.

Nearly all studies in Table 2 use ready-made LCIA methods. But few elaborate on the robustness and uncertainties of different LCIA methods or how they relate to each other. In this context, it is important to point out that impact categories relating to vehicle tailpipe emissions, such as global warming, are both well-established (Hauschild et al. 2013) and co-varying. Resource-related impact categories are more complex. For abiotic resource depletion, improvements in LCIA characterization methods are needed (Hauschild et al. 2013), as there are data gaps regarding several metals and dependency on old data. In the case of human toxicity, there are many uncertainties related to data availability and aggregation procedure.

A final methodological observation made from Table 2 is the dominance of studies concerning cars for individual transportation. Other vehicle types, such as heavy duty trucks and buses, remain to be explored.

\subsection{Lessons for stakeholders}

WTW studies demonstrate that greenhouse gas emissions from vehicles in general reduce as electrification of the powertrain increases, but the main lesson is that this improvement is heavily dependent on the fossil content of the electricity mix. Thus, if and only if electricity production becomes free of fossil carbon on a global scale, electrified vehicles with external charging capability, such as BEVs and PHEVs, can reach their full potential in mitigating global warming. Surprisingly, few studies make this a main conclusion and clearly communicate the obvious message that environmental benefits from largescale deployment of electric vehicles is strongly dependent on parallel improvements of the background energy system to key stakeholders such as policy makers, the automotive and power industries, as well as the general public as customers.

In addition, WTW studies show that driving behavior and traffic situation is important. Electrified powertrains are most beneficial in city traffic, with stop-start driving and low speed, being a perfect match with built-in reduction of local tailpipe emissions and limited range. Moreover, complete LCA studies point out the increased importance of the manufacturing stage, and that the benefits of electric propulsion increase with the lifetime driven distance. As batteries feature partly calendar-dependent aging, this indicates it is most beneficial to make use of electric powertrains in vehicles that are intensively used. This conclusion is of particular importance to policy design, as well as strategies in the automotive sector, e.g., which market sectors benefit most from incentives and investments, and how to balance the size of the electric and ICE powertrains in PHEV designs.

On the whole, studies providing more extensive impact assessment confirm the important role of electricity production. WTW electricity is generally the dominating factor in impact categories relating to airborne emissions. However, with regard to resource use and toxicity issues, policy makers and the automotive industry ought to be aware that aspects related to mining can become an area with significant adverse impacts on the environmental performance of electric vehicles in the future. Efforts made to improve these practices and minimize leakage of toxic substances from mine tailings are beneficial for hybrid and electric vehicles. A geopolitical dimension is thereby linked to LCA study recommendations because mining activities are concentrated to certain regions of the world.

This is true also for resource availability and efficiency. Notably, the LCIA of resources in its current form accentuates fossil energy and does not reveal constraints on minerals such as lithium or rare earth metals, which may become critical to large-scale deployment of electric and hybrid vehicles in the future. A conclusion relevant to policy makers, the automotive industry, and the recycling industry is that establishing a proper recycling system for lithium batteries and other components is yet another key to success.

Lastly, the frequent lack of time perspective in existing LCA studies should be noted by all stakeholders and in particular policy makers. Improvements in production processes, both due to progress in manufacturing technology and benefits of scale, may decrease the future environmental load of electric powertrains significantly in different life cycle stages. The background energy system will also continue to change. 


\subsection{Key conclusions}

This review shows that many LCA studies of electric and hybrid vehicles have been conducted. The discussion reveals that the answers provided by any study depend on both technical and methodological scope, indicating that a clearly stated purpose is crucial. However, comprehensive goal formulation is very often left out in current studies. The time scopes of the assessments are also often omitted. This makes it difficult to determine the temporal validity of results and conclusions. In addition, electric powertrain technology is not fully developed and emerging, while most studies consider current technology used in today's electricity production system. Consequently, there is a lack of future time perspective, for example concerning advances in material processing, manufacturing of parts, and changes in electricity production. In a final remark on methodology, it can be observed that environmental impact assessment coupled to obtaining resources is an area with a lack of knowledge and a need for more research.

As regards assessment results, this knowledge gap is a cause of uncertainty suggesting that processes related to resource handling might become targeted for improvements. In mining, leakage of substances from mine tailings poses a risk for toxic emissions. Also, recycling may avoid future constraints on key resources and reduce production energy demand, but the realization of efficient recycling of electrified vehicles remains as a future challenge. Finally, the most obvious conclusion is that electricity production is the main cause of environmental impact for externally chargeable vehicles. All studies can agree on one crucial message - only if the global electricity production is made clean and essentially free from emissions of fossil carbon, these vehicles can reach their full potential in mitigating global warming.

\begin{abstract}
Acknowledgments The authors would like to thank Mats Wiliander and Steven Sarasini for their comments on previous versions of the text, Rickard Arvidsson for details about the toxicity issue, and Duncan Kushnir for specifics about lithium-ion battery manufacturing. We express our gratitude to Björn Sandén for planting valuable ideas and for his comments on overall scope and previous text versions. Finally, we thank all anonymous reviewers for valuable observations.
\end{abstract}

Open Access This article is distributed under the terms of the Creative Commons Attribution License which permits any use, distribution, and reproduction in any medium, provided the original author(s) and the source are credited.

\section{References}

Althaus H-J (2012) Modern individual mobility. Int J Life Cycle Assess 17(3):267-269

Andrews SD (2006) Life cycle assessment and the design of ultra-low and zero emission vehicles in the UK. Thesis for the degree of
Doctor of Philosophy, Imperial College of Science, Technology and Medicine at University of London, London, UK

Baptista P, Ribau J, Bravo J, Silva C, Adcock P, Kells A (2011) Fuel cell hybrid taxi life cycle analysis. Energy Pol 39(9):4683-4691

Baptista P, Silva C, Gonçalves G, Farias T (2009) Full life cycle analysis of market penetration of electricity based vehicles. World Electr Veh 3(1):1-6

Bartolozzi I, Rizzi F, Frey M (2013) Comparison between hydrogen and electric vehicles by life cycle assessment: a case study in Tuscany, Italy. Appl Energy 101:103-111

Boureima F, Messagie M, Sergeant N, Matheys J, Mierlo J. Van, Vos M. De, Caevel BD, Turcksin L, Macharis C (2012) Environmental assessment of different vehicle technologies and fuels. In: Longhurst JWS, Brebbia CA (eds) Urban transport XVII, Urban Transport and the Environment in the 21st Century, 15-17 May 2012. WIT Transactions on The Built Environment. WIT Press, pp 15-25

Boureima FS, Messagie M, Matheys J, Wynen V, Sergeant N, Van Mierlo J, De Vos M, De Caevel B (2009) Comparative LCA of electric, hybrid, LPG and gasoline cars in Belgian context. World Electr Veh $3(1): 1-8$

Brandão M, Heath G, Cooper J (2012) What can meta-analyses tell us about the reliability of life cycle assessment for decision support? J Ind Ecol 16(S1):S3-S7

Brinkman N, Wang M, Weber T, Thomas Darlington (2005) Well-towheels analysis of advanced fuel/vehicle systems - a North American study of energy use, greenhouse gas emissions, and criteria pollutant emission. May 1, 2005. General Motors Corporation and Argonne National Laboratory, USA

Chan CC (2007) The state of the art of electric, hybrid, and fuel cell vehicles. Proc IEEE 95(4):704-718

Chan S, Miranda-Moreno LF, Alam A, Hatzopoulou M (2013) Assessing the impact of bus technology on greenhouse gas emissions along a major corridor: a lifecycle analysis. Transp Res Part D 20:7-11

Cicconi P, Landi D, Morbidoni A, Germani M (2012) Feasibility analysis of second life applications for Li-ion cells used in electric powertrain using environmental indicators. In: ENERGYCON 2012, IEEE International Energy Conference \& Exibition, Florence, Italy, 9-12 September 2012. pp 985-990

Classen M, Althaus H-J, Blaser S, Scharnhorst W, Tuchschmid M, Jungbluth N, Emmenegger MF (2009) Life cycle inventories of metals. March, 2009: Ecoinvent report No. 10. Swiss Centre for Life Cycle Inventories, Dübendorf. (Data v2.1)

Cooney G, Hawkins TR, Marriott J (2013) Life cycle assessment of diesel and electric public transportation buses. J Ind Ecol. doi:10.1111/jiec. 12024

Corrigan DA, Masias A (2011) Batteries for electric and hybrid electric vehicles. In: Reddy TB (ed) Linden's handbook of batteries, 4th edn. McGraw Hill, New York

Cuenca R, Formento J, Gaines L, Marr B, Santini D, Wang M, Adelman S, Kline D, Mark J, Ohi J, Rau N, Freeman S, Humphreys K, Placet M (1998) Total energy cycle assessment of electric and conventional vehicles: an energy and environmental analysis. ANL, NREL, PNNL report. vol 1. Argonne National Laboratory, National Renewable Energy Laboratory and Pacific Northwest National Laboratory for U.S. Department of Energy and U.S. Office of Energy Efficiency and Renewable Energy, USA. (Tecnical report ANL/ES/RP—96387-Vol.1). doi:10.2172/627823

Daniel JJ, Rosen MA (2002) Exergetic environmental assessment of life cycle emissions for various automobiles and fuels. Exergy Int J 2(4): 283-294

Dewulf J, Van der Vorst G, Denturck K, Van Langenhove H, Ghyoot W, Tytgat J, Vandeputte K (2010) Recycling rechargeable lithium ion batteries: critical analysis of natural resource savings. Resour Conserv Recycl 54(4):229-234 
Dones R, Bauer C, Bollinger R, Burger B, Heck T, Röder A, Emmenegger M, Frischknecht R, Jungbluth N, Tuchschmid M (2007) Life cycle inventories of energy systems: results for current systems in Switzerland and other UCTE countries. 2007: Ecoinvent report No. 5. Swiss Centre for Life Cycle Inventories. (Data v2.0)

Duce AD, Egede P, Öhlschläger G, Dettmer T, Althaus H-J, Bütler T, Szczechowicz E (2013) eLCAr - guidelines for the LCA of electric vehicles. January 31, 2013: Proj.no. 285571. (Report from project "E-Mobility Life Cycle Assessment Recommendations", funded within the European Union Seventh Framework ProgrammeFP7/2007-2013)

Dunn JB, Gaines L, Sullivan J, Wang MQ (2012) Impact of recycling on cradle-to-gate energy consumption and greenhouse gas emissions of automotive lithium-ion batteries. Environ Sci Technol 46(22): 12704-12710

Edwards R, Larivé J-F, Beziat J-C (2011a) Well-to-wheels analysis of future automotive and powertrains in the European context-wellto-wheels report version 3C. EUR - scientific and technical research series. July, 2011a: ISSN 1831-9424. Publications Office of the European Union, Luxembourg. (ISBN 978-92-79-21395-3, reported by Joint Research Centre of the European Commission, EUCAR and CONCAWE) doi:10.2788/79018

Edwards R, Larivé J-F, Beziat J-C (2011b) Well-to-wheels analysis of future automotive and powertrains in the European context-wellto-wheels appendix 2 version 3C, WTW GHG-emissions of externally chargeable electric vehicles. EUR - scientific and technical research series. July, 2011b: ISSN 1831-9424. Publications Office of the European Union, Luxembourg. (ISBN 978-92-79-21395-3, reported by Joint Research Centre of the European Commission, EUCAR and CONCAWE) doi:10.2788/79018

Edwards R, Mahieu V, Griesemann J-C, Larivé J-F, Rickeard DJ (2004) Well-to-wheels analysis of future automotive fuels and powertrains in the European context. SAE Technical Paper. 2004. SAE International. (SAE Technical Paper 2004-01-1924 reported by CONCAWE, EUCAR and JRC) doi:10.4271/2004-01-1924

Elgowainy A, Han J, Poch L, Wang M, Vyas A, Mahalik M, Rousseau A (2010) Well-to-wheels analysis of energy use and greenhouse gas emissions of plug-in hybrid electric vehicles. vol ANL/ESD/10-1. June 1, 2010. Argonne National Laboratory, U.S. Department of Energy, Argonne

European Parliament (2008) Position of the European parliament. The European Parliament and the Council of the European Union, European Union. Reg. EP-PE_TC1-COD(2007)0297, PE 417.788

Faria R, Marques P, Moura P, Freire F, Delgado J, de Almeida AT (2013) Impact of the electricity mix and use profile in the life-cycle assessment of electric vehicles. Renew Sust Energ Rev 24:271-287

Faria R, Moura P, Delgado J, de Almeida AT (2012) A sustainability assessment of electric vehicles as a personal mobility system. Energy Convers Manag 61:19-30

Farrell AE, Plevin RJ, Turner BT, Jones AD, O'Hare M, Kammen DM (2006) Ethanol can contribute to energy and environmental goals. Science 311(5760):506-508

Finnveden G, Hauschild MZ, Ekvall T, Guinée J, Heijungs R, Hellweg S, Koehler A, Pennington D, Suh S (2009) Recent developments in life cycle assessment. J Environ Manag 91(1):1-21

Frischknecht R, Flury K (2011) Life cycle assessment of electric mobility: answers and challenges-Zurich, April 6, 2011. Int J Life Cycle Assess 16(7):691-695

Gaines L, Sullivan J, Burnham A, Belharouak I (2011) Life-cycle analysis of production and recycling of lithium ion batteries. Transp Res Rec J Transp Res Board 2252:57-65

Gao L, Winfield ZC (2012) Life cycle assessment of environmental and economic impacts of advanced vehicles. Energies 5(3):605-620

Geyer R, Stoms D, Kallaos J (2013) Spatially-explicit life cycle assessment of sun-to-wheels transportation pathways in the U.S. Environ Sci Technol 47(2):1170-1176
GM, ANL, BP, ExxonMobile, Shell (2001) Well-to-wheel energy use and greenhouse gas emissions of advanced fuel/vehicle systems - North American analysis-executive summary report. vol 1. 2001. General Motors Corporation (GM) and Argonne National Laboratory (ANL), USA. (Conducted by ANL's Center for Transportation Research and commissioned by GM with Dr. James P. Wallace III, Wallace \& Associates, as Program manager.)

Goedkoop M, Spriensma R (2001) The Eco-indicator 99: a damage oriented method for life cycle assessment - methodology report. June 22, 2001: nr 1999/36A. PRé Consultants B.V., Amersfoort, The Netherlands

Goedkoop MJ, Heijungs R, Huijbregts M, De Schryver A, Struijs J, Van Zelm R (2012) ReCiPe 2008, A life cycle impact assessment method which comprises harmonised category indicators at the midpoint and the endpoint level-Report I: characterisation. First (revised) edn. VROM, The Netherlands

Graedel TE, Allwood J, Birat J-P, Buchert M, Hagelüken C, Reck BK, Sibley SF, Sonnemann G (2011) What do we know about metal recycling rates? J Ind Ecol 15(3):355-366

Guinée JB, Gorrée M, Heijungs R, Huppes G, Kleijn R, Koning Ad, Oers Lv, Wegener Sleeswijk A, Suh S, Udo de Haes HA, Bruijn Hd, Duin Rv, Huijbregts MAJ (2002) Handbook on life cycle assessment. Operational guide to the ISO standards. I: LCA in perspective. IIa: Guide. IIb: Operational annex. III: Scientific background. Guinée JB. Centrum Milieukunde Leiden (CML), Leiden University. Kluwer, Dordrecht

Hackney J, de Neufville R (2001) Life cycle model of alternative fuel vehicles: emissions, energy, and cost trade-offs. Transp Res Part A 35(3):243-266

Harto C, Meyers R, Williams E (2010) Life cycle water use of low-carbon transport fuels. Energy Pol 38(9):4933-4944

Hauschild M, Goedkoop M, Guinée J, Heijungs R, Huijbregts M, Jolliet O, Margni M, Schryver A, Humbert S, Laurent A, Sala S, Pant R (2013) Identifying best existing practice for characterization modeling in life cycle impact assessment. Int J Life Cycle Assess 18(3):683-697

Hawkins T, Gausen O, Strømman A (2012) Environmental impacts of hybrid and electric vehicles - a review. Int J Life Cycle Assess 17(8):997-1014

Hawkins TR, Singh B, Majeau-Bettez G, Strømman AH (2013a) Comparative environmental life cycle assessment of conventional and electric vehicles. J Ind Ecol 17(1):53-64

Hawkins TR, Singh B, Majeau-Bettez G, Strømman AH (2013b) Corrigendum to: Hawkins, T. R., B. Singh, G. Majeau-Bettez, and A. H. Strømman. 2012. Comparative environmental life cycle assessment of conventional and electric vehicles. J Ind Ecol 17(1): $158-160$

Hearron JD, McDonough M, Ranjbar A, Wei W, Chenjie L, Shamsi P, Manohar S, Fahimi B (2011) The sustainability of new technologies in vehicular transportation. In: 2011 I.E. Vehicle Power and Propulsion Conference, Piscataway, NJ, USA, 6-9 Sept. 2011. 2011 I.E. Vehicle Power and Propulsion Conference. IEEE. doi: 10.1109/vppc.2011.6043194

Heijungs R, Huijbregts MAJ (2004) A review of approaches to treat uncertainty in LCA. In Complexity and Integrated Resources Management. In: Pahl-Wostl C, Schmidt S, Rizzoli AE, Jakeman AJ (eds) Complexity and Integrated Resources Management, University of Osnabrück, Germany, 14-17 June 2004. International Environmental Modelling and Software Society, Manno, Switzerland, pp 332-339

Held M, Baumann M (2011) Assessment of the environmental impacts of electric vehicle concepts. In: Finkbeiner M (ed) Towards life cycle sustainability management, 1st edn. Springer, Dordrecht, pp 535546. doi:10.1007/978-94-007-1899-9 52

Helland $\AA$ (2009) Well-to-wheel $\mathrm{CO}_{2}$ analysis of electric and ICE vehicles: are global $\mathrm{CO}_{2}$ emission reductions possible? Int J Glob Warm 1(4):432-442 
Hellsing J (2013) Senior technical specialist electric drive systems, Volvo Group Trucks Technology, Volvo Group. Personal communication with Nordelöf A. March 13 and August 22, 2013

Helmers E, Marx P (2012) Electric cars: technical characteristics and environmental impacts. Environ Sci Eur 24(4):1-15

Hillman KM, Sanden BA (2008) Time and scale in life cycle assessment: the case of fuel choice in the transport sector. Int J Altern Propuls 2(1):1-12

Huijbregts MAJ, Thissen U, Guinée JB, Jager T, Kalf D, van de Meent D, Ragas AMJ, Wegener Sleeswijk A, Reijnders L (2000) Priority assessment of toxic substances in life cycle assessment. Part I: calculation of toxicity potentials for 181 substances with the nested multi-media fate, exposure and effects model USES-LCA. Chemosphere 41(4):541-573

Huo H, Wu Y, Wang M (2009) Total versus urban: well-to-wheels assessment of criteria pollutant emissions from various vehicle/fuel systems. Atmos Environ 43(10):1796-1804

IAE (2011) Technology Roadmap - electric and plug-in hybrid electric vehicles. June, 2011. International Energy Agency, OECD/IEA, France

ISO (2006a) Environmental management - life cycle assessment - principles and framework, ISO 14040:2006. International Organization for Standardization, Geneva

ISO (2006b) Environmental management-life cycle assessment-requirements and guidelines, ISO 14044:2006. International Organization for Standardization, Geneva

Jaramillo P, Samaras C, Wakeley H, Meisterling K (2009) Greenhouse gas implications of using coal for transportation: life cycle assessment of coal-to-liquids, plug-in hybrids, and hydrogen pathways. Energy Pol 37(7):2689-2695

Jolliet O, Margni M, Charles R, Humbert S, Payet J, Rebitzer G, Rosenbaum R (2003) IMPACT 2002+: a new life cycle impact assessment methodology. Int J Life Cycle Assess 8(6):324-330

Karbowski D, Haliburton C, Rousseau A (2008) Impact of component size on plug-in hybrid vehicle energy consumption using global optimization. World Electr Veh 2(2)

Kintner-Meyer M, Schneider K, Pratt R (2007) Impacts assessment of plug-in hybrid vehicles on electric utilities and regional US power grids, Part 1: Technical analysis. November, 2007. Pacific Northwest National Laboratory, USA.

Kliucininkas L, Matulevicius J, Martuzevicius D (2012) The life cycle assessment of alternative fuel chains for urban buses and trolleybuses. J Environ Manag 99:98-103

Kobayashi S, Plotkin S, Ribeiro S (2009) Energy efficiency technologies for road vehicles. Energy Efficiency 2(2):125-137

Kudoh Y, Nansai K, Kondo Y, Tahara K (2007) Life cycle $\mathrm{CO}_{2}$ emissions of FCEV, BEV and GV in actual use. Paper presented at the 23rd International Battery, Hybrid and Fuel Cell Electric Vehicle Symposium \& Exposition, Anaheim, California, 2-5 Dec

Kushnir D, Sandén BA (2011) Multi-level energy analysis of emerging technologies: a case study in new materials for lithium ion batteries. J Clean Prod 19(13):1405-1416

Lane B (2006) Life cycle assessment of vehicle fuels and technologies. Final report. Ecolane transport consultancy on behalf of London Borough of Camden. London, UK

Lave L, MacLean H, Hendrickson C, Lankey R (2000) Life-cycle analysis of alternative automobile fuel/propulsion technologies. Environ Sci Technol 34(17):3598-3605

Li L, Dunn JB, Zhang XX, Gaines L, Chen RJ, Wu F, Amine K (2013) Recovery of metals from spent lithium-ion batteries with organic acids as leaching reagents and environmental assessment. J Power Sources 233:180-189

Lloyd SM, Ries R (2007) Characterizing, propagating, and analyzing uncertainty in life-cycle assessment: a survey of quantitative approaches. Ind Ecol 11(1):161-179

Ma H, Balthasar F, Tait N, Riera-Palou X, Harrison A (2012) A new comparison between the life cycle greenhouse gas emissions of battery electric vehicles and internal combustion vehicles. Energy Pol 44:160-173

Maas H (2013) AW: inquiry regarding calculations made in Edwards et al. 2011 WTW study Appendix 2. E-mail sent to Nordelöf A. Tuesday 23rd of April at 16:57, 2013

Machacek E (2012) Potential ecodesign directive contributions to resource-efficient innovations - a case study on the electric motor product group expansion and rare earth element use in permanent magnet motors. Thesis for the fulfilment of the Master of Science in Environmental Management and Policy, Lund University, Lund, Sweden, September 2012

MacLean HL, Lave LB (2003) Life cycle assessment of automobile/fuel options. Environ Sci Technol 37(23):5445-5452

MacPherson ND, Keoleian GA, Kelly JC (2012) Fuel economy and greenhouse gas emissions labeling for plug-in hybrid vehicles from a life cycle perspective. J Ind Ecol 16(5):761-773

Majeau-Bettez G, Hawkins T, Hammer Strømman A (2011) Life cycle environmental assessment of lithium-ion and nickel metal hydride batteries for plug-in hybrid and battery electric vehicles. Environ Sci Technol 45(10):4548-4554

Matheys J, Timmermans J-M, Van Mierlo J, Meyer S, Van den Bossche P (2009) Comparison of the environmental impact of five electric vehicle battery technologies using LCA. Int J Sust Manuf 1(3): 318-329

Matheys J, Van Autenboer W, Timmermans JM, Van Mierlo J, Van Den Bossche P, Maggetto G (2007) Influence of functional unit on the life cycle assessment of traction batteries. Int J Life Cycle Assess 12(3):191-196

Matheys J, Van Mierlo J, Timmermans J-M, Van den Bossche P (2008) Life-cycle assessment of batteries in the context of the EU directive on end-of-life vehicles. Int J Veh Des 46(2):189-203

Matsuhashi R, Kudoh Y, Yoshida Y, Ishitani H, Yoshioka M, Yoshioka K (2000) Life cycle of $\mathrm{CO}_{2}$-emissions from electric vehicles and gasoline vehicles utilizing a process-relational model. Int J Life Cycle Assess 5(5):306-312

McCleese D, LaPuma P (2002) Using Monte Carlo simulation in life cycle assessment for electric and internal combustion vehicles. Int $\mathrm{J}$ Life Cycle Assess 7(4):230-236

McKenzie EC, Durango-Cohen PL (2012) Environmental life-cycle assessment of transit buses with alternative fuel technology. Transp Res Part D 17(1):39-47

Messagie M (2013) Environmental performance of electric vehicles, a life cycle system approach. Thesis for the award of the degree of Doctor in engineering, Vrije Universiteit Brussel, Belgium

Messagie M, Boureima F, Matheys J, Sergeant N, Timmermans JM, Macharis C, Van Mierlo J (2011) Environmental performance of a battery electric vehicle: a descriptive life cycle assessment approach. World Electr Veh 4(1):782-786

Messagie M, Boureima F, Matheys J, Sergeant N, Turcksin L, Macharis C, Van Mierlo J (2010) Life cycle assessment of conventional and alternative small passenger vehicles in Belgium. Paper presented at the 2010 I.E. Vehicle Power and Propulsion Conference, VPPC 2010, Lille, 1-3 Septembere

Messagie M, Lebeau K, Boureima F, Sergeant N, Macharis C, Van Mierlo $J$ (2012) Influence of the uptake of electric vehicles on the impact on climate change of an entire future vehicle fleet, a 2020 Brussels perspective. Paper presented at the EVS26, Los Angeles, California, May 6-9, 2012

Mousazadeh H, Keyhani A, Mobli H, Bardi U, Lombardi G, el Asmar T (2009) Environmental assessment of RAMseS multipurpose electric vehicle compared to a conventional combustion engine vehicle. J Clean Prod 17(9):781-790

National Research Council (2013) Transitions to alternative vehicles and fuels. The National Academies Press, Washington DC, USA

Nemry F, Brons M (2010) Plug-in hybrid and battery electric vehiclesmarket penetration scenarios of electric drive vehicles. JRC 
Technical Note. European Commission, Luxembourg. (Draft technical note JRC/IPTS JRC58748)

Nonaka T, Nakano M (2010) Study of popularization policy of clean energy vehicles using life cycle assessment. Paper presented at the Third International Conference on Infrastructure Systems and Services: Next Generation Infrastructure Systems for Eco-Cities (INFRA), 2010, Shenzhen, China, 11-13 November

Notter DA, Gauch M, Widmer R, Wäger P, Stamp A, Zah R, H-Jr A (2010a) Contribution of li-ion batteries to the environmental impact of electric vehicles. Environ Sci Technol 44(17):6550 6556

Notter DA, Gauch M, Widmer R, Wäger P, Stamp A, Zah R, Althaus H-Jr (2010b) Supporting information to the manuscript entitled contribution of li-ion batteries to the environmental impact of electric vehicles. EMPA - The Swiss Federal Laboratories for Materials Science and Technology, Switzerland. (Supporting Information for Environmental Science \& Technology)

Ou X, Yan X, Zhang X (2010a) Using coal for transportation in China: life cycle GHG of coal-based fuel and electric vehicle, and policy implications. Int J Greenh Gas Con 4(5):878-887

Ou X, Zhang X, Chang S (2010b) Alternative fuel buses currently in use in China: life-cycle fossil energy use, GHG emissions and policy recommendations. Energy Pol 38(1):406-418

Prakash R, Henham A, Bhat IK (2005) Gross carbon emissions from alternative transport fuels in India. Energy Sustain Dev 9(2): $10-16$

Querini F, Dagostino S, Morel S, Rousseaux P (2012) Greenhouse gas emissions of electric vehicles associated with wind and photovoltaic electricity. Energy Procedia 20:391-401

Querini F, Morel S, Boch V, Rousseaux P (2011) Global, regional and local environmental impacts: LCA indicators for energy \& mobility. Paper presented at the LCM 2011-Towards Life Cycle Sustainability Management, Berlin, 28-31 August

Raykin L, MacLean HL, Roorda MJ (2012) Implications of driving patterns on well-to-wheel performance of plug-in hybrid electric vehicles. Environ Sci Technol 46(11):6363-6370

Sadek N (2012) Urban electric vehicles: a contemporary business case. Eur Transp Res Rev 4(1):27-37

Samaras C, Meisterling K (2008a) Life cycle assessment of greenhouse gas emissions from plug-in hybrid vehicles: implications for policy. Environ Sci Technol 42(9):3170-3176

Samaras C, Meisterling K (2008b) Life cycle assessment of greenhouse gas emissions from plug-in hybrid vehicles: implications for policy-supporting Online Information. Carnegie Mellon University, Pittsburgh, Pennsylvania, USA. (Supporting Information for Environmental Science \& Technology)

Sandén BA (2008) Standing the test of time: signals and noise from environmental assessments of energy technologies. In: life-cycle analysis for new energy conversion and storage systems, Boston, MA, 26-27 November 2007. MRS, pp 183-189

Schneider L, Berger M, Finkbeiner M (2011) The anthropogenic stock extended abiotic depletion potential (AADP) as a new parameterisation to model the depletion of abiotic resources. Int $\mathrm{J}$ Life Cycle Assess 16(9):929-936

Sharma R, Manzie C, Bessede M, Crawford RH, Brear MJ (2013) Conventional, hybrid and electric vehicles for Australian driving conditions. Part 2: Life cycle CO2-e emissions. Transp Res Part C 28:63-73

Shen W, Han W, Chock D, Chai Q, Zhang A (2012) Well-to-wheels lifecycle analysis of alternative fuels and vehicle technologies in China. Energy Pol 49:296-307

Simon B, Weil M (2013) Analysis of materials and energy flows of different lithium ion traction batteries. Rev Metall 110(1):65-76

Sioshansi R, Denholm P (2009) Emissions impacts and benefits of plugin hybrid electric vehicles and vehicle-to-grid services. Environ Sci Technol 43(4):1199-1204
Spielmann M, Althaus H-J (2007) Can a prolonged use of a passenger car reduce environmental burdens? Life cycle analysis of Swiss passenger cars. J Clean Prod 15:1122-1134

Stephan CH, Sullivan J (2008) Environmental and energy implications of plug-in hybrid-electric vehicles. Environ Sci Technol 42(4):11851190

Sterman JD (1991) A skeptic's guide to computer models. In: Barney GO, Kreutzer WB, Garrett MJ (eds) Managing a nation: the microcomputer software catalog, 2nd edn. Westview, Boulder, pp 209-229

Sullivan JL, Burnham A, Wang M (2010) Energy-consumption and carbon-emission analysis of vehicle and component manufacturing (trans: Center for Transportation Research ESD). ANL report. Argonne National Laboratory, U.S. Department of Energy, Argonne, Illinois. (GREET VMA model report ANL/ESD/10-6)

Sullivan JL, Gaines L (2010) A review of battery life-cycle analysis: state of knowledge and critical needs (trans: Center for Transportation Research ESD). ANL report. Argonne National Laboratory, U.S. Department of Energy, Argonne, Illinois. (Review report ANL/ $\mathrm{ESD} / 10-7)$

Sullivan JL, Gaines L (2012) Status of life cycle inventories for batteries. Energy Convers Manag 58:134-148

Sullivan JL, Gaines L, Burnham A (2011) Role of recycling in the life cycle of batteries. In: TMS 2011-140th Annual Meeting and Exhibition, San Diego, CA, 2011. TMS 2011-140th Annual Meeting and Exhibition. pp 25-32

Szczechowicz E, Dederichs T, Schnettler A (2012) Regional assessment of local emissions of electric vehicles using traffic simulations for a use case in Germany. Int J Life Cycle Assess 17(9):1131-1141

Tahara K, Sinha S, Sakamoto R, Kojima T, Taneda K, Funasaki A, Ohtaki $\mathrm{T}$, Inaba A (2001) Comparison of $\mathrm{CO}_{2}$ emissions from alternative and conventional vehicles. World Resour Rev 13(1):52-60

Tillman AM (2000) Significance of decision-making for LCA methodology. Environ Impact Assess 20(1):113-123

Timmermans J-M, Matheys J, Van Mierlo J, Lataire P (2006) Environmental rating of vehicles with different fuels and drive trains: a univocal and applicable methodology. Eur J Transp Infrastruct Res 6(4):313-334

Tran M, Banister D, Bishop JDK, McCulloch MD (2012) Realizing the electric-vehicle revolution. Nat Clim Chang 2(5):328-333

Van den Bossche P, Vergels F, Van Mierlo J, Matheys J, Van Autenboer W (2006) SUBAT: an assessment of sustainable battery technology. J Power Sources 162(2 SPEC. ISS):913-919. doi:10.1016/j. jpowsour.2005.07.039

Van Mierlo J, Boureima F, Sergeant N, Wynen V, Messagie M, Govaerts L, Denys T, Vanderschaeghe M, Macharis C, Turcksin L, Hecq W, Englert M, Lecrombs F, Klopfert F, De Caevel B, De Vos M (2009) Clean vehicle research: LCA and policy measures "CLEVER"Science for a Sustainable Development-Transport \& Mobility, Final Report Phase 1. Belgian Science Policy, Brussels. (Research Programme Science for a Sustainable Development report SD/TM/ 04A)

Van Mierlo J, Timmermans JM, Maggetto G, Van den Bossche P, Meyer S, Hecq W, Govaerts L, Verlaak J (2004) Environmental rating of vehicles with different alternative fuels and drive trains: a comparison of two approaches. Transp Res Part D 9(5):387-399

Van Mierlo J, Vereecken L, Maggetto G, Favrel V, Meyer S, Hecq W (2003a) Comparison of the environmental damage caused by vehicles with different alternative fuels and drivetrains in a Brussels context. Proc Inst Mech Eng, Part D 217(7):583-594

Van Mierlo J, Vereecken L, Maggetto G, Favrel V, Meyer S, Hecq W (2003b) How to define clean vehicles? Environmental impact rating of vehicles. Int J Automot Technol 4:77-86

Van Vliet O, Brouwer AS, Kuramochi T, Van Den Broek M, Faaij A (2011) Energy use, cost and $\mathrm{CO}_{2}$ emissions of electric cars. J Power Sources 196(4):2298-2310 
Vetter J, Novák P, Wagner MR, Veit C, Möller KC, Besenhard JO, Winter M, Wohlfahrt-Mehrens M, Vogler C, Hammouche A (2005) Ageing mechanisms in lithium-ion batteries. J Power Sources 147(1-2): 269-281

Williamson SS, Emadi A (2005) Comparative assessment of hybrid electric and fuel cell vehicles based on comprehensive well-towheels efficiency analysis. IEEE Trans Veh Technol 54(3): $856-862$

Volkswagen Group (2012) The e-Mission. Electric mobility and the environment. July, 2012: Art. No. 27412450118. Group
Research Environmental Affairs Product in cooperation with Group Electric Traction, Volkswagen Group, Wolfsburg, Germany. http://www.volkswagenag.com/content/vwcorp/info center/en/publications/publications.acq.html/icp-2/index.html. Accessed 27 Aug 2013

Zackrisson M, Avellán L, Orlenius J (2010) Life cycle assessment of lithium-ion batteries for plug-in hybrid electric vehicles - critical issues. J Clean Prod 18(15):1517-1527

Zumsteg JM, Cooper JS, Noon MS (2012) Systematic review checklist. J Ind Ecol 16(S1):S12-S21 